\title{
The molecular genetics of Marfan syndrome and related microfibrillopathies
}

\author{
Peter N Robinson, Maurice Godfrey
}

\begin{abstract}
Mutations in the gene for fibrillin-1 (FBN1) have been shown to cause Marfan syndrome, an autosomal dominant disorder of connective tissue characterised by pleiotropic manifestations involving primarily the ocular, skeletal, and cardiovascular systems. Fibrillin-1 is a major component of the $10-12 \mathrm{~nm}$ microfibrils, which are thought to play a role in tropoelastin deposition and elastic fibre formation in addition to possessing an anchoring function in some tissues.
\end{abstract}

Fibrillin-1 mutations have also been found in patients who do not fulfil clinical criteria for the diagnosis of Marfan syndrome, but have related disorders of connective tissue, such as isolated ectopia lentis, familial aortic aneurysm, and Marfan-like skeletal abnormalities, so that Marfan syndrome may be regarded as one of a range of type 1 fibrillinopathies.

There appear to be no particular hot spots since mutations are found throughout the entire fibrillin-1 gene. However, a clustering of mutations associated with the most severe form of Marfan syndrome, neonatal Marfan syndrome, has been noted in a region encompassing exons 24 to 32 . The gene for fibrillin-2 $(F B N 2)$ is highly homologous to FBN1, and mutations in FBN2 have been shown to cause a phenotypically related disorder termed congenital contractural arachnodactyly. Since mutations in the fibrillin genes are likely to affect the global function of the microfibrils, the term microfibrillopathy may be the most appropriate to designate the spectrum of disease associated with dysfunction of these molecules.

The understanding of the global and the molecular functions of the fibrillin containing microfibrils is still incomplete and, correspondingly, no comprehensive theory of the pathogenesis of Marfan syndrome has emerged to date. Many, but not all, fibrillin-1 gene mutations are expected to exert a dominant negative effect, whereby mutant fibrillin monomers impair the global function of the microfibrils. In this paper we review the molecular physiology and pathophysiology of Marfan syndrome and related microfibrillopathies.

(F Med Genet 2000;37:9-25)

Keywords: Marfan syndrome; fibrillin; microfibrillopathies

\section{Marfan syndrome}

Marfan syndrome (MFS) is an autosomal dominant heritable disorder of connective tissue that involves primarily the skeletal, ocular, and cardiovascular systems. The leading cause of premature death in MFS patients is progressive dilatation of the aortic root and ascending aorta, causing aortic incompetence and dissection. ${ }^{12}$ MFS has an incidence of at least $1: 10000$ and about $25-30 \%$ of cases represent new mutations. ${ }^{3}$

A wide variety of skeletal abnormalities occurs with MFS, including dolichostenomelia, arachnodactyly, scoliosis, chest wall deformity (pectus carinatum or excavatum), tall stature, ligamentous laxity, abnormal joint mobility, and protrusio acetabulae. Scoliosis is found in about $60 \%$ of adults of both sexes with MFS. ${ }^{4}$ Pectus excavatum of some degree of severity occurs in about two thirds of all MFS patients, and may have a greater tendency to recur after surgical repair than idiopathic pectus excavatum.

Ectopia lentis occurs in up to about $80 \%$ of MFS patients and is almost always bilateral. ${ }^{6}$ The most common cardiovascular manifestations of MFS affect the atrioventricular valves and the aorta. Mitral valve disease may be the earliest of the cardiovascular manifestations of MFS. Progressive dilatation of the aortic root is responsible for most cases of aortic incompetence; usually, there is a gradual dilatation starting at the aortic root which may extend into the ascending aorta. This may then lead to the sudden onset of aortic dissection, which can cause acute aortic regurgitation or aortic rupture with sudden death. ${ }^{2}$ Generalised aortic root dilatation ${ }^{7}$ as well as a family history of severe cardiovascular disease in relatives with $\mathrm{MFS}^{8}$ are associated with a greater risk for aortic complications.

The average life expectancy has risen significantly since $1972,{ }^{9}$ which is at least in part because of the benefits arising from cardiovascular surgery ${ }^{10}$ and medical therapy with beta blockers. ${ }^{11} 12$

The diagnosis of MFS can be made according to the criteria of the Gent nosology when major criteria are present in two organ systems and a third organ system is involved. ${ }^{13}$ Diagnostic dilemmas may arise because of the considerable inter- and intrafamilial variability of MFS. Also, many features of MFS, such as mitral valve prolapse or scoliosis, are common in the general population or may occur in other connective tissue disorders. Many manifestations are age dependent, and therefore the clinical criteria as defined in the Gent nosology cannot always be strictly applied to paediatric 


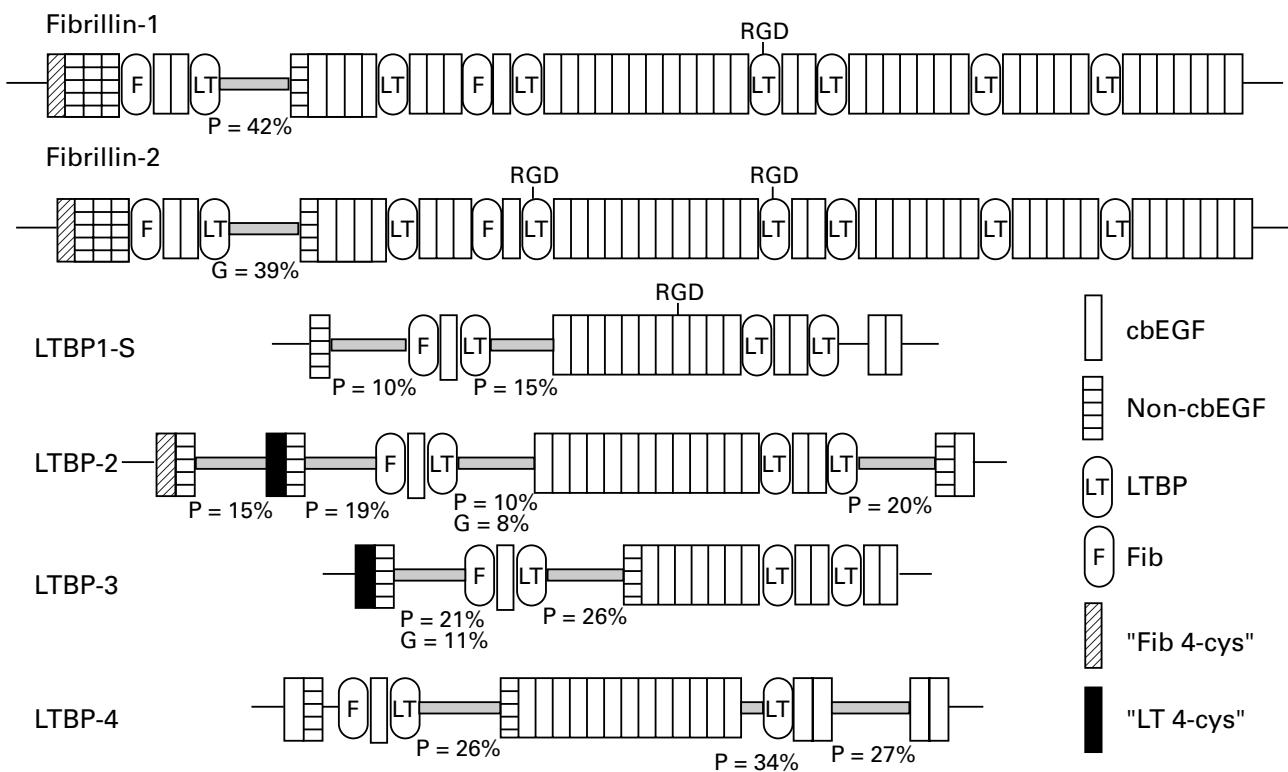

Figure 1 Domain structure of proteins of the fibrillin and latent transforming growth factor $\beta 1$ binding protein (LTBP) families. Fibrillin-1, ${ }^{22}$ fibrillin-2, ${ }^{32}$ LTBP-1S, ${ }^{194}$ LTBP-2, ${ }^{56}$ LTBP-3, ${ }^{59}$ and LTBP-4 ${ }^{61}$ are shown. All proteins were sketched from the human sequence, except for LTBP-3, for which the human sequence has not yet been completely determined. In addition to the symbols shown in the figure, grey horizontal rectangles are used to denote sequences at least 40 amino acids long with an unusually high content of proline $(P)$ or glycine $(G)$; the approximate percentage of these residues is indicated underneath the corresponding rectangles. Horizontal lines denote unique sequences in the $N$-or $C$-terminal regions or elsewhere.

patients. This is particularly true in the case of children with sporadically occurring disease. ${ }^{14}$

\section{The identification of the fibrillin-1 gene (FBN1)}

Several strategies led to the identification of the fibrillin-1 gene (FBN1) in 1991. Fibrillin, a $350 \mathrm{kDa}$ glycoprotein, was discovered in 1986 and characterised as the main component of the extracellular microfibrils. ${ }^{15}$ By means of immunohistochemical studies with monoclonal antibodies against fibrillin, it was shown in 1990 that most Marfan patients display abnormalities of the microfibrils in the extracellular matrix. ${ }^{16} \mathrm{~A}$ peptide from fibrillin was isolated from which a 20 amino acid sequence could be determined; this allowed appropriate combinations of PCR primers to be designed. One combination led to the amplification of a PCR product, which was used as a probe to isolate a $1.6 \mathrm{~kb} \mathrm{cDNA}$ fragment belonging to the fibrillin-1 gene that was then assigned to chromosome $15 q 15-21$ by in situ hybridisation. ${ }^{17}$ By this time, linkage analysis had mapped the MFS gene to the long arm of chromosome 15 in $1990,{ }^{18}{ }^{19}$ making the fibrillin-1 gene a promising candidate gene for MFS. Finally, Dietz et a $2^{0}$ showed a de novo point mutation in the fibrillin-1 gene in two unrelated Marfan patients.
The structure of the fibrillin-1 gene The fibrillin-1 gene (FBN1, previously Fib15) spans about $200 \mathrm{~kb}$ genomic DNA ${ }^{21}$ with 65 exons and a transcript size of $10 \mathrm{~kb}$. The mRNA possesses 9663 nucleotides with an open reading frame of 8613 nucleotides and 5' and $3^{\prime}$ untranslated regions of 134 and $916 \mathrm{nt}^{22}$ Fibrillin-1, the protein product of FBN1, is a cysteine rich monomeric glycoprotein with a molecular weight of about $350 \mathrm{kDa}^{23}$ Profibrillin-1 contains 2871 amino acids and can be divided into a signal peptide for extracellular secretion and five structurally distinct domains ${ }^{22}$ (A-E). Domains B and D are composed of repeated motifs, which can be divided into three groups based on sequence homology (table 1). The first type of motif, termed epidermal growth factor-like motif (EGF), occurs 47 times in fibrillin-1; EGF motifs contain six highly conserved cysteine residues which form disulphide bridges with one another. Forty three of the 47 EGF repeats of fibrillin-1 also contain a calcium binding consensus sequence ${ }^{24}$ and are termed calcium binding EGF-like motifs (cbEGF). The second structural motif is analogous to a motif first described in the latent transforming growth factor- $\beta 1$ binding protein (LTBP motif, also referred to as 8-cys or TGF $\beta 1$ bp motif) and contains eight cysteine residues with an internal cluster of three consecutive cysteine

Table 1 Consensus sequences for motifs shared between the fibrillins and the LTBPs. Consensus sequences were determined from sequences taken from the references cited in fig 1 . In the consensus sequences, $X$ may be any residue and the numbers in parentheses indicate an average number of residues

\begin{tabular}{|c|c|c|}
\hline Motif & Proteins & Consensus sequence \\
\hline $\begin{array}{l}\text { EGF } \\
\text { cbEGF } \\
\text { LTBP } \\
\text { Fib } \\
\text { Fib 4-cys motif } \\
\text { LT 4-cys motif }\end{array}$ & $\begin{array}{l}\text { Fibrillin-1,2, LTBP-1, }-2,-3,-4 \\
\text { Fibrillin-1,2, LTBP-1, }-2,-3,-4 \\
\text { Fibrillin-1,2, LTBP-1, -2, -3, }-4 \\
\text { Fibrillin-1,2, LTBP-1, }-2,-3,-4 \\
\text { Fibrillin-1,2, LTBP-2 } \\
\text { LTBP-2,-3 }\end{array}$ & 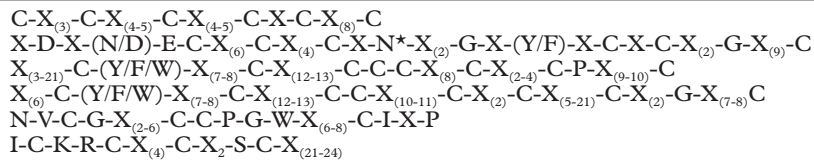 \\
\hline
\end{tabular}


residues. Seven LTBP modules occur in fibrillin domains B and D. The LTBP motifs display a globular structure and interrupt multiple tandem stretches of cbEGF modules that are thought to form rod-like structures. ${ }^{25}$ The fourth LTBP motif contains an RGD (arginine-glycine-aspartic acid) cell adhesion motif. RGD motifs interact with cell surface receptors of the integrin family to mediate cell adhesion. Integrins are transmembrane proteins which can interact with proteins of the extracellular matrix and with elements of the cytoskeleton, resulting in an anchoring of cells within the extracellular matrix (ECM) ${ }^{26}$ The RGD motif of fibrillin-1 was shown to promote cell adhesion via integrin $\alpha_{v} \beta_{3}{ }^{27-29}$

The third structural motif may represent a fusion of portions of the EGF and LTBP motifs $^{22}$ and has been termed the Fib motif. Like the LTBP motif, the Fib motif contains eight cysteine residues, two of which are clustered together in the same relative location as the three consecutive cysteine residues of the LTBP repeat. A nine cysteine derivative of the Fib motif is found in domain B.

Exon 1 contains the ATG start site for translation and codes for a signal peptide followed by a consensus processing sequence for propeptides $\mathrm{RX}(\mathrm{K} / \mathrm{R}) \mathrm{R} \downarrow$; in vitro evidence suggests that fibrillin-1 undergoes intracellular $\mathrm{N}$-terminal processing at this site..$^{30}$ The cleavage site is followed by 12 mainly basic amino acids of unknown functional significance (domain A).

Domain B (exons 2-10) begins with a four cysteine motif with some similarities to the Fib motif, and also contains three non-calcium binding EGF-like motifs and the first two cbEGF motifs, a nine cysteine derivative of the Fib motif, and the first LTBP-like motif.

Domain C (exon 10) is characterised by an unusually high proline content $(42 \%)$. It has been speculated that the high proline content may allow region $\mathrm{C}$ to bend in three dimensional space and act as a kind of molecular hinge. $^{31}$

Domain D represents the largest single domain and comprises 2240 amino acids grouped in 49 cysteine rich repeats, comprising one non-calcium binding EGF-like motif and 41 cbEGF motifs, six LTBP-like motifs, and one Fib motif (exons 11-63).

The carboxy-terminal domain $\mathrm{E}$ (exons 64-65) represents a unique sequence which contains a pair of two consecutive cysteine residues within a sequence which is highly conserved between fibrillin-1 and fibrillin-2 (see below). This high level of conservation between the two fibrillins suggests that the region may possess a specific functional significance. $^{32}$ In addition, the carboxyterminus contains a stretch of basic amino acids harbouring a tetrabasic cleavage site (RKRR $\downarrow)$, which undergoes extracellular cleavage by an enzyme of the PACE (Paired basic Amino acid Cleaving Enzyme) convertase family. ${ }^{33-36}$

Fibrillin- 1 contains 14 sites for $N$-linked glycosylation, the majority of which are located in domain D. ${ }^{22}$ Some, but not all, putative
$N$-glycosylation sites in normal profibrillin are used during its regular intracellular posttranslational processing. ${ }^{37}$ Also, a specific Asn residue forming a part of this calcium binding consensus sequence is $\beta$ hydroxylated. ${ }^{38}$

\section{The fibrillin-2 gene (FBN2)}

The fibrillin-2 gene (FBN2, previously Fib5) on chromosome $5 \mathrm{q} 23-\mathrm{q} 31$ is closely related to fibrillin-1 (fig 1). The domain structure as well as the number and order of the sequence motifs are identical between the two proteins. Domains B and D of fibrillin-1 and -2 are $80 \%$ identical at the amino acid level. However, fibrillin-1 and -2 have important differences, which may reflect differing functional roles. Fibrillin-1 contains one RGD motif and fibrillin-2 contains two. Whereas domain $\mathrm{C}$ of fibrillin-1 is proline rich, domain $\mathrm{C}$ of fibrillin-2 contains a high content of glycine residues. ${ }^{32}$ Domains A and E are comparatively less related to the corresponding domains of fibrillin-1 (19\% and 50\% amino acid identity).

Fibrillin-1 and fibrillin-2 are differentially expressed, both in terms of developmental stages and tissue distribution. In most cases, developmental expression of the fibrillin genes exhibits a diphasic pattern, with the onset of $F B N 2$ expression occurring earlier than $F B N 1$ expression. FBN2 transcripts seem to accumulate before tissue differentiation and to decrease rapidly or disappear thereafter; FBN1 transcripts increase at a gradual rate thereafter. Fibrillin-2 is found preferentially in elastic tissues, such as the elastic cartilage, the tunica media layer of the aorta, and along the bronchial tree. ${ }^{39}$ The two fibrillins may therefore have differing functional roles; fibrillin-2 may possess a major functional role during early morphogenesis in directing elastic fibre assembly ${ }^{40}$; in contrast, the predominance of fibrillin-1 in stress and load bearing structures, like the aortic adventitia, the ciliary zonules, and the skin, suggests that fibrillin-1 may be mainly responsible for the structural function of the microfibrils. ${ }^{39}$

\section{A second locus for MFS on chromosome 3?}

Linkage to chromosome 3p24.2-p25 has been shown in a large family with a Marfan-like phenotype for whom linkage to the fibrillins had been previously excluded. ${ }^{41-43}$ While a cumulative lod score of $>150$ for linkage between fibrillin-1 and MFS makes genetic heterogeneity unlikely in classical MFS, ${ }^{44}$ it will not be surprising that mutations in other genes may cause non-classical Marfan-like phenotypes.

\section{The latent transforming growth factor- $\beta$ binding protein (LTBP) genes}

The fibrillins are structurally related to the LTBP gene family. To date, four LTBP genes have been identified, all of which contain multiple tandem copies of the cbEGF motif as well as two different eight cysteine repeats found to date only in fibrillin and in the LTBPs. The first of these, the LTBP motif, contains eight cysteine residues with an internal cluster of three 
consecutive cysteines. The second motif, termed "Fib motif" because it was first described in fibrillin- $1,{ }^{22}$ contains eight cysteine residues with an internal cluster of two consecutive cysteines. The terminology surrounding these motifs can be confusing, especially since the LTBP motif and Fib motif have occasionally been lumped together as " 8 cys repeats" or "TGF repeats". Table 1 supplies a summary of the consensus sequences of the motifs found in the fibrillins and LTBPs. It is noteworthy that the order of the EGF motifs and the eight cysteine repeats in the LTBPs is similar to that in the fibrillins (fig 1).

LTBP-1 was initially characterised as a regulator of transforming growth factor- $\beta$ (TGF- $\beta$ ) metabolism. TGF- $\beta$ is a family of proteins that regulate growth, differentiation, adhesion, and migration of various cell types. Although TGF- $\beta$ is growth inhibitory for most cell types, it can stimulate the production of extracellular matrix proteins, such as the collagens, fibronectin, elastin, and tenascin.

TGF- $\beta$ is synthesised in a precursor form that undergoes self-association followed by endoproteolytic cleavage to form two disulphide bonded homodimers: mature TGF- $\beta$ and the $\mathrm{N}$-terminal propeptide of the TGF- $\beta$ precursor. The N-terminal propeptide is termed latency-associated peptide (LAP), since it renders secreted TGF- $\beta$ latent by remaining non-covalently associated with it to form the small latent TGF- $\beta$ complex. The large latent complex additionally contains LTBP-1, a monomeric molecule that is covalently attached to the LAP by means of an exchange of cysteine disulphide bonds between the third LTBP (eight cysteine) repeat and the LAP during secretion. ${ }^{45} 46$

LTBP-1 undergoes rapid intracellular association with TGF- $\beta$, which augments the secretion of TGF- $\beta$ from cells. ${ }^{47}$ Following secretion, LTBP-1 is able to store latent TGF- $\beta$ in the extracellular matrix. ${ }^{48} 49$ LTBPECM interaction may be an important intermediate step in TGF- $\beta$ activation..$^{50}$ Release of TGF- $\beta$ from the ECM as a consequence of proteolytic cleavage of LTBP-1 is one possible mechanism for the regulation of TGF- $\beta$ action. ${ }^{51}{ }^{52}$ LTBP-1 may also participate in the activation of latent TGF- $\beta$ by concentrating it on the cell surface where activation occurs. ${ }^{53}$

In addition to its role as a regulator of TGF- $\beta$ metabolism, there is evidence that LTBP-1 has a distinct role as an independent structural protein of the ECM. LTBP-1 and TGF- $\beta 1$ co-localise not only with fibronectin and collagen type IV, but also with $10 \mathrm{~nm}$ diameter structures thought to represent fibrillin-associated microfibrils. ${ }^{54}$ The binding of LTBP-1 to the ECM is mediated by a covalent interaction localised to its amino terminal domain. ${ }^{45}$ An alternatively spliced form of LTBP-1, which is longer in its amino terminal domain (LTBP-1L), binds even more efficiently to the ECM. ${ }^{55}$

To date, little is known about the differential functional roles of the four LTBP isoforms, although LTBP-2, -3 , and -4 share at least some of the functional properties of LTBP-1. LTBP-2 also forms a large, latent TGF- $\beta$ com- plex and can associate with the ECM..$^{56}$ Bovine LTBP-2 localises to elastin-associated microfibrils of the bovine nuchal ligament, and is bound covalently to the microfibrils by reducible disulphide linkages. Interestingly, the LTBP-2 was found not to bind to latent TGF- $\beta$, but appeared to be an independent structural component of the microfibrils. ${ }^{57}$ Like LTBP-1, LTBP-2 binds to the ECM via its amino-terminal domain and can be released from the ECM by proteolysis. ${ }^{58}$ Like LTBP-1 and -2 , LTBP- 3 can also bind to the TGF- $\beta 1$ precursor, ${ }^{59}$ and this interaction also appears to be mediated by an LTBP motif. ${ }^{60}$ Finally, a fourth LTBP has been identified ${ }^{61}$ and appears also to undergo association with the extracellular matrix. ${ }^{62}$

Many of these microfibrillar elements localise to fibrillin-containing microfibrils. Therefore, they can be considered candidate genes for many of the disorders, named and unnamed, that clinically overlap with MFS. Preliminary studies based on such an approach are described later.

\section{Elastic fibres, microfibrils, and fibrillin}

The elastic fibre is a complex structure, which contains elastin, 10-12 nm microfibrils, lysyl oxidase, and perhaps proteoglycans. By electron microscopy, elastic fibres can be seen to be composed of two morphologically distinct components: an amorphous fraction lacking any regular structure and constituting about $90 \%$ of the mature fibre, which consists exclusively of elastin, and a microfibrillar component consisting of 10-12 nm microfibrils. Elastin-producing cells secrete tropoelastin, the $70 \mathrm{kDa}$ monomeric precursor of elastin, into the extracellular space, where it is rapidly accreted to the surface of elastic fibres and becomes highly cross linked by the action of lysyl oxidase to form mature elastin. Elastin endows the elastic fibres with the property of elastic recoil, which is essential for the function of resilient tissues, such as the aorta, the lung, and the skin. ${ }^{63}$ The $10-12 \mathrm{~nm}$ microfibrils are located primarily around the periphery of the amorphous elastin component of the elastic fibres. The microfibrils display a "beads on a string" structure with a diameter of 8 to $12 \mathrm{~nm}$ and consist of several distinct proteins including fibrillin. Morphologically identical microfibrils have been found in association with elastin in a wide variety of tissues, including skin, lung, kidney, blood vessels, cartilage, and tendon. Microfibrils not associated with elastin may be observed in other tissues, such as the ciliary zonule. ${ }^{15}$

Whereas the role of elastin in mediating elastic recoil of tissues is well established, the functions of the microfibrils are not yet fully understood. The microfibrils do appear to subserve several global functions. First, they act as a scaffolding for tropoelastin deposition and elastic fibre formation. ${ }^{64}$ Second, microfibrils themselves are extensible, ${ }^{65}$ and they may contribute to the mechanical properties of mature elastic tissues by means of load redistribution between individual elastic fibres. ${ }^{66}$ Third, they provide structural anchorage in non-elastic tis- 
sues, such as the ciliary zonules. ${ }^{67}$ Fourth, microfibrils may serve to anchor endothelial and epithelial cells to elastic fibres of the ECM via cell binding domains. ${ }^{28}$ Fifth, a role for the microfibrils in the provision of a flexible mechanical anchor at epithelial-mesenchymal basement membrane interfaces, such as at the dermal epidermal junction, has been proposed.$^{68}$ In addition, a role for fibrillin containing microfibrils in the support of platelet adhesion has been reported. ${ }^{69}$

In addition to fibrillin-1 and -2 , a series of other proteins has been isolated from the microfibrils (table 2). Microfibril associated glycoprotein 1 (MAGP-1) is a $31 \mathrm{kDa}$ glycoprotein consisting of two domains: an acidic $\mathrm{N}$-terminal domain without cysteine residues and a basic C-terminal domain containing all 13 cysteine residues. ${ }^{70}$ MAGP-1 appears to be covalently bound to the microfibrils by intermolecular disulphide links ${ }^{71} 72$ and is also a substrate for transglutaminase, ${ }^{73}$ although it is not known which component of the microfibrils undergoes crosslinking with MAGP-1. Since the N-terminal region of MAGP-1 can undergo binding with both tropoelastin ${ }^{73}$ and type VI collagen, ${ }^{74}$ it is possible that MAGP-1 is responsible for the organisation of tropoelastin monomers in the ECM before cross linking ${ }^{75}$ as well as playing a role in the interaction of fibrillin containing microfibrils and type VI collagen, which forms extensive networks of 3-5 $\mathrm{nm}$ microfibrils in virtually all soft connective tissues. MAGP-1 localises specifically to the "beads" of isolated microfibrils, and multiple MAGP-1 molecules may be present in a single bead. ${ }^{76}$

The fact that dermal microfibrils contain gene products of both $F B N 1$ and $M A G P-1$ is underlined by observations in early immunofluorescence studies of MFS patients. In these studies, abnormal (decreased) immunostaining results were noticed when antibodies to either fibrillin or $M A G P-1$ were used (Godfrey and Hollister, unpublished data). Thus MAGP-1 was as good a candidate as fibrillin in the quest for the aetiology of MFS. To date, however, there are no reports of mutations in $M A G P-1$.

MAGP-2 is a $25 \mathrm{kDa}$ glycoprotein that is also disulphide-bonded to fibrillin containing microfibrils. ${ }^{77}$ There is a close similarity between MAGP-1 and MAGP-2 confined to a central region of 60 amino acids in the C-terminal domain including a precise alignment of seven cysteine residues. ${ }^{78}$ MAGP-2 does not appear to possess tropoelastin or type VI collagen binding properties, but instead possesses an RGD cell adhesion motif in its $\mathrm{N}$ terminal domain which can interact with a range of cell types via $\alpha_{v} \beta_{3}$ integrin. ${ }^{79}$ MAGP-2 has a more restricted tissue and developmental distribution than MAGP-1, which may reflect its presumed differing functional roles. ${ }^{80}$

The microfibril-associated protein 1 $(M F A P-1)$ is a $58 \mathrm{kDa}$ protein that is apparently post-translationally cleaved to a 32 $\mathrm{kDa}$ fragment that becomes an integral component of microfibrils. ${ }^{81} M F A P-1$ does not appear to share sequence homology or domains with other known proteins, but is characterised by a large amount of glutamic acid residues (22\%) as well as a clustering of lysine residues on the C terminal region. ${ }^{82}$ Human $M F A P-1$ does not contain any cysteine residues. Interestingly, $M F A P-1$ was mapped to chromosome $15 \mathrm{q} 15-$ q21, the same region as FBN1, which made $M F A P-1$ an alternative positional candidate gene for MFS. However, extensive mutation analysis failed to show mutations in $M F A P-1$ in MFS patients, thus ruling out this locus as a reservoir for hidden MFS mutations. ${ }^{83}$

$M F A P 2$ is an earlier designation for $M A G P$ 1. MFAP3 consists of merely two exons encoding a protein of 362 amino acids that displays no homology to other known proteins. The gene is located on chromosome 5q32-q33.2, near to the locus 5q21-q31 reported for the fibrillin-2 gene. ${ }^{84}$ At present it is not known if the co-localisation of the genes FBN2 and MFAP3 (or of the genes FBN1 and MFAP1 on chromosome 15q15-21) has some functional significance. Interestingly, the gene for the above mentioned lysyl oxidase is located on chromosome 5q23.2-q31.2, whereas a newly discovered lysyl oxidase-like (LOL) gene has been mapped to chromosome 15q24-q25. The function and tissue specificity of the LOL protein remain to be elucidated. ${ }^{8}$

MFAP4 is a $36 \mathrm{kDa}$ glycoprotein whose tissue distribution appears to be highest in the aortic adventitia. ${ }^{86}$ MFAP4 has a fibrinogenlike domain and an RGD cell adhesion motif in its $\mathrm{N}$-terminal domain. MFAP4 is one of the genes deleted in the contiguous gene syndrome of Smith-Magenis. ${ }^{87}$

A family of microfibril-associated proteins termed aortic aneurysm antigenic proteins (AAAP) with distribution limited to the aorta has been identified and preliminary results have been presented. ${ }^{88} 89$

While the above proteins, and perhaps one or more of the LTBPs, are thought to be integral components of the elastin-associated microfibrils, a number of molecules has been shown to co-localise with these microfibrils or to be able specifically to bind to them (table 3 ).

Table 2 Protein components of fibrillin-containing associated microfibrils

\begin{tabular}{llllll}
\hline No & Protein & Localisation & Exons & Size & Remarks \\
\hline $1^{1522}$ & Fibrillin-1 & $15 \mathrm{q} 15-21$ & 65 & $350 \mathrm{kDa}, 2871$ amino acids & RGD motif \\
$2^{32}$ & Fibrillin-2 & $5 \mathrm{q} 23-\mathrm{q} 31$ & 65 & $350 \mathrm{kDa}$ & 2 RGD motifs \\
$3^{73195}$ & MAGP-1 (MFAP-2) & $1 \mathrm{p} 36$ & 9 & $31 \mathrm{kDa}$ & 13 cysteine residues \\
$4^{77}$ & MAGP-2 & $12 \mathrm{p} 12.3-12 \mathrm{p} 13.2$ & 9 & $25 \mathrm{kDa}$; 173 amino acids & RGD motif \\
$5^{8182}$ & MFAP-1 & $15 \mathrm{q} 15-\mathrm{q} 21$ & 9 & 439 amino acids & 22\% glutamic acid \\
$6^{84}$ & MFAP-3 & $5 \mathrm{q} 32-\mathrm{q} 33.2$ & 2 & 362 amino acids & 23\% glutamic acid; $\%$ aspartic acid \\
$7^{8687}$ & MFAP-4 & $17 \mathrm{p} 11.2$ & $?$ & $36 \mathrm{kDa} ; 255$ amino acids & RGD motif \\
$8^{88}$ & AAAP-40, rAAAP-CL4 & $?$ & $?$ & $?$ & Not yet well characterised
\end{tabular}

MAGP $=$ microfibril associated glycoprotein MFAP $=$ microfibril associated protein; AAAP-40 $=$ aortic aneurysm associated protein-40. 
A specific binding interaction with fibrillin-1 has been shown for two proteins of the ECM. Fibulin-2 is a four domain ECM protein which is able to form disulphide-linked homodimers. ${ }^{90}$ Fibulin-2 appears not to be an integral component of the microfibrils, but was shown to co-localise with fibrillin-containing microfibrils in some, but not all tissues. ${ }^{91}$ In regenerating skin, fibulin-2 associates with fibrillin-containing microfibrils only at late stages of skin morphogenesis. ${ }^{92}$ Fibulin-2 specifically binds to the N-terminal region of fibrillin-1. ${ }^{91}$ Since fibulin-2 was also shown to bind with a distinct affinity to fibronectin, ${ }^{93}$ it seems possible that fibulin-2 plays a connecting role between various ECM proteins, as has been hypothesised for fibulin-1, which can undergo binding with laminin, ${ }^{94}$ nidogen, ${ }^{95}$ fibrinogen, ${ }^{96}$ and fibronectin ${ }^{97}$ as well as self-association. ${ }^{98}$ Interestingly, fibulin-1 was identified within the amorphous core of elastic fibres, similar to elastin, but not in the fibrillincontaining microfibrils. ${ }^{99}$

An interaction of region $\mathrm{C}$ of fibrillin with laminin $\beta 2$ was identified by yeast two hybrid analysis and confirmed with a protein based affinity assay. Since the laminins are found in basement membranes and fibrillin-containing microfibrils insert into basement membranes, a biological significance for this finding seems possible. ${ }^{100}$ The laminins are ubiquitous components of the basement membranes and appear to play a role in protein-protein and cell-matrix interactions. ${ }^{101}$

A series of other proteins has been reported to co-localise or to associate with fibrillincontaining microfibrils. Emilin (elastin microfibril interface located protein), a $115 \mathrm{kDa}$ glycoprotein, associates with the elastinmicrofibril interface. Emilin appears early in embryogenesis and may be involved in elastogenesis. ${ }^{102} 103$

Fibrillin-containing microfibrils were shown to be closely associated with a chondroitin sulphate proteoglycan; at present neither the nature of the proteoglycan nor whether its protein core or glycose amino glycan chain(s) is responsible for the association with fibrillin is known. ${ }^{104}$ Interestingly, the expression of decorin may be altered in cases of neonatal Marfan syndrome ${ }^{105}{ }^{106}$; as decorin is a member of the small proteoglycan family, it would seem to be a particularly interesting candidate for the proteoglycan association partner. ${ }^{104}$

Versican, a large aggregating proteoglycan, showed an apparent co-localisation with the elastic network of the dermis in human skin. Since anti-versican antibodies also stained

Table 3 Molecules which may be able to associate with fibrillin or fibrillin containing microfibrils

\begin{tabular}{lll}
\hline No & Protein & References \\
\hline 1 & LTBP-1 & 55194 \\
2 & LTBP-2 & 56 \\
3 & LTBP-3 & 59 \\
4 & LTBP-4 & 61 \\
5 & Fibulin-2 & 91 \\
6 & Laminin $\beta 2$ & 100 \\
7 & Emilin & 102 \\
8 & Versican & 107 \\
9 & Chondroitin sulphate proteoglycan & 104 \\
\hline
\end{tabular}

structure resembling microfibrils owing to their oxytolan staining, an association with microfibrils appears very likely. ${ }^{107}$

\section{Fibrillin polymers as components of the microfibrils}

The mechanisms involved in the assembly of fibrillin monomers into polymeric structures have been among the most controversial topics in the field. The key questions include whether fibrillin monomers are arranged in a parallel, head to tail manner or if they form an antiparallel arrangement; whether the monomers are staggered or in register; the sequence of steps involved in polymerisation; the location of selfassociation sites on fibrillin; if polymerisation occurs by self-assembly or if other proteins or cells are required; what portion of the beads on a string structure of the microfibrils is made up of fibrillin; and how the other components of the microfibrils interact with fibrillin. Although much progress has been made since the discovery of fibrillin in 1986, many of the above questions still remain unanswered.

Taken together, the published evidence speaks strongly for fibrillin monomers polymerising in a parallel, head to tail conformation rather than in an antiparallel fashion. Immunoelectron microscopy with a combination of two monoclonal antibodies shows a periodicity which is only compatible with a head to tail conformation. ${ }^{30}$ By examination with different monoclonal antibodies it was shown that the $\mathrm{N}$ - and C-termini of fibrillin-1 are located in the immediate vicinity and on either side of the beads of the microfibrils, with one bead per fibrillin monomer. ${ }^{30}$

The fact that individual fibrillin monomers possess a width of $2.2 \mathrm{~nm}$ and the microfibrils a width of $10-12 \mathrm{~nm}^{23}$ suggests that the microfibrils may consist of a bundle of individual fibrillin monomers, which is supported by the electron microscopic observation of multiple fibrillin monomers being associated with a single bead. ${ }^{76} 108$ It remains to ask whether individual, head to tail filaments of fibrillin monomers are arranged in a staggered or an in register fashion within the microfibrils; the evidence reported to date seems to support a combination of these two arrangements.

At least two forms of intermolecular linkage occur in fibrillin microfibrils. Within hours of the extracellular secretion of fibrillin monomers, aggregates are formed which are stabilised by intermolecular disulphide bridges that are not reducible. Fibrillin is thus a covalently bound integral component of the microfibrils. ${ }^{65}$ Probably, multiple fibrillin monomers are associated with a single bead. ${ }^{76108}$

Homodimerisation of the N-terminal domain of fibrillin- 1 or -2 appears to be the first step in microfibril assembly and is mediated by disulphide bonding. ${ }^{109}$ The notion of homodimers with an unstaggered alignment is also supported by observations on the tight skin mouse, which carries an in frame duplication of mouse Fbn1 exons 17-40, since wild type monomers do not appear to be able to polymerise with mutant monomers of a correspondingly increased length. ${ }^{110}$ 
In addition to disulphide bonds, $\alpha$-glutamyl$\varepsilon$-lysine crosslinks are also present in fibrillincontaining microfibrils ${ }^{111}$ and result from modification of fibrillin by transglutaminase. ${ }^{112}$ The cross links were shown to localise to the interbead regions in a way consistent with a parallel staggered arrangement of fibrillin monomers in the microfibrils. ${ }^{113}$ One way of reconciling the data would be a model in which individual monomers form parallel, unstaggered dimers that in turn associate with other dimers in a staggered fashion.

Whatever the arrangement of fibrillin monomers may be, evidence has underlined the importance of lateral monomer to monomer interactions. FBN1 mutations causing skipping of one or more exons are associated with an almost complete absence of higher molecular weight aggregates in the ECM fraction in cell culture, ${ }^{114} 115$ which suggests that the correct lateral alignment of fibrillin monomers may be necessary for the assembly of multimeric aggregates. This is compatible with the observation that in frame exon skipping mutations tend to be associated with severe clinical phenotypes. ${ }^{116}$

Although some issues have been settled concerning the aggregation of fibrillin monomers into multimeric structures, very little is known concerning the interaction of fibrillin with other integral protein components of the microfibrils such as MAPG-1 and -2; to date, it has not been possible to show specific binding interactions.

FBN1 mutations in Marfan syndrome and related type 1 fibrillinopathies

With a few exceptions, all known FBN1 mutations identified to date have been unique, which probably reflects the high mutation rate of the fibrillin-1 gene and the impaired reproductive fitness of MFS patients owing to early morbidity and mortality. As of 1998,137 mutations have been entered in the international Marfan database (http:// www.umd.necker.fr) for FBN1 mutations. ${ }^{117}$ Only 11 of the 137 entries represent recurrent mutations.

The mutations identified to date have been found in almost all exons of the fibrillin-1 gene. Aside from a mild clustering of excess mutations in exons 25,27 , and $28,{ }^{117}$ the mutations identified to date appear to be spread across the gene with no clear predilection for any one area of the gene. ${ }^{44} 118119$

For reasons that are still not completely understood, mutations have been found in only a minority of patients analysed to date. Following the discovery of the fibrillin-1 gene in 1991, numerous reports on cDNA based mutation analysis of the fibrillin-1 gene in Marfan patients appeared; the sensitivity of mutation detection, when indicated, was between 10 and $25 \% .{ }^{120}{ }^{121}$ In 1995 , the first report on exonwise screening of all 65 FBN1 exons was published; a detection rate of $78 \%$ in a group of nine patients was reported. ${ }^{122}$ However, a subsequent study could duplicate this result only in a small group of well characterised, multigeneration Marfan families (7/9); for the entire group of 60 unrelated patients and families, only 17 probable disease causing mutations were found $(28 \%)$, suggesting that overdiagnosis of Marfan syndrome may be responsible for the low overall mutation detection rate. ${ }^{123}$ Other factors, such as the large size of the gene and the large number of exons, may also be partially responsible for the low efficiency of mutation detection in Marfan patients.

The majority of mutations identified to date represent missense mutations (99/137 or $72 \%)$; of these, most affect one of the numerous cbEGF modules dispersed throughout the protein $(73 / 137$ or $53 \%)$. Mutations predicted to lead to premature protein truncation including nonsense mutations and out of frame deletions represent a small proportion of mutations. Exon skipping mutations, associated mainly with mutations affecting splicing consensus sequences, are relatively common $(18 / 137$ or $13 \%)$. Although mutations of consensus splice sequences are the most common cause of aberrant splicing in human genetic disease, several instances of exon skipping associated with nonsense mutations in the skipped exons have been reported, including one nonsense mutation in FBN1 exon 51. ${ }^{124} 125$ Unusually, a "silent" mutation in the same exon also was shown to cause skipping of exon 51 in a patient with classical MFS. ${ }^{126}$

Clear genotype-phenotype correlations have been slow to emerge. In light of the high intrafamilial variability, it is to be assumed that environmental and perhaps epigenetic factors play a significant role in determining the severity of the phenotype in a patient with a given mutation. In addition to mutations found in patients with classical MFS phenotypes, FBN1 mutations have been found in a series of related connective tissue disorders, termed type 1 fibrillinopathies (table 4).

Neonatal Marfan syndrome (nMFS) represents the severest end of the spectrum of MFS and is characterised by a series of manifestations, which are rare in classical MFS. Patients with $\mathrm{nMFS}$ are typically diagnosed at or shortly after birth and present with symptoms such as mitral or tricuspid insufficiency, congestive heart failure, pulmonary emphysema, joint contractures, crumpled ears, and loose skin. Death occurs usually within the first year of life. ${ }^{127} 128$ In contrast to classical MFS, where death in untreated patients is most often because of aortic dissection or rupture following progressive aortic root dilatation, the primary cause of death for children with nMFS is severe congestive heart failure owing to mitral and tricuspid regurgitation. If one uses a strict clinical definition of $\mathrm{nMFS}$, there is a clustering of mutations in exons 24-27, where missense mutations as well as small deletions and one exon skipping mutation have been detected in nMFS patients, as well as exon skipping mutations in exons $31-32 .{ }^{127}$

Patients carrying exon skipping mutations tend to have severe phenotypes, ${ }^{116}$ and five of the reported nMFS mutations are exon skipping mutations. It appears likely that in frame exon skipping mutations may disrupt the lateral alignment of fibrillin monomers and 
Table 4 Type 1 fibrillinopathies

\begin{tabular}{|c|c|c|c|c|}
\hline No & Syndrome & Clinical features & Mutations & Refs \\
\hline 1 & Marfan syndrome & See text, section 1 & See text, section 10 & 117 \\
\hline 2 & Neonatal MFS (nMFS) & $\begin{array}{l}\text { Severe manifestations (see text). Death usually in the first year of life } \\
\text { owing to congestive heart failure. }\end{array}$ & $\begin{array}{l}\text { "Hotspot" in ex 24-27 } \\
\text { and } 31-32\end{array}$ & Reviewed in 127 \\
\hline 3 & Shprintzen-Goldberg syndrome & Craniosynostosis and marfanoid habitus & C1223Y (ex 29) & 133 \\
\hline 4 & Familial arachnodactyly & Arachnodactyly, dolichostenomelia, no cardiovascular manifestations & $\mathrm{R} 1170 \mathrm{H}(\mathrm{ex} 28)$ & 137 \\
\hline 5 & Ectopia lentis & $\begin{array}{l}\text { Bilateral ectopia lentis, in some cases scoliosis, no cardiovascular } \\
\text { manifestations }\end{array}$ & E2447K (ex 59) & 131 \\
\hline 6 & $\begin{array}{l}\text { Ascending aortic aneurysm and } \\
\text { dissection without classical MFS }\end{array}$ & $\begin{array}{l}\text { Ascending aortic aneurysm and dissection, no ectopia lentis, no specific } \\
\text { skeletal findings }\end{array}$ & $\begin{array}{l}\text { (1) G1127S (ex 27) } \\
\text { (2) D1155N (ex 27) } \\
\text { (3) P1837S (ex 44) }\end{array}$ & 139141 \\
\hline 7 & MASS phenotype & $\begin{array}{l}\text { Mitral valve prolapse, aortic root dilatation without dissection, skeletal } \\
\text { and skin abnormalities }\end{array}$ & 5317insTTCA (ex 41) & 151 \\
\hline 8 & New variant of the MFS & $\begin{array}{l}\text { Skeletal features of MFS with joint contractures and knee joint effusions. } \\
\text { Ectopia lentis. no cardiovascular manifestations }\end{array}$ & R122C (ex 4) (2x) & 196197 \\
\hline 9 & Isolated skeletal features & Tall stature, scoliosis, pectus excavatum, arachnodactyly & R2726W (ex 64) & 33 \\
\hline
\end{tabular}

thereby cause a radical disruption of microfibril formation. ${ }^{116}$

Autosomal dominant ectopia lentis refers to bilateral ectopia lentis without the typical skeletal and cardiovascular manifestations of the MFS. ${ }^{129}$ This disease is linked to the fibrillin-1 gene. ${ }^{130}$ To date, the responsible FBN1 mutation could be identified in just one affected family. ${ }^{131}$ The mutation is predicted to substitute the fifth residue of the cbEGF module encoded by exon 59 from glutamic acid to lysine (E2447K). The position within the affected module and the type of residue substitution are not sufficient to explain the phenotype, since a mutation in the cbEGF module encoded by exon 26 , which is predicted to substitute the analogous glutamic acid residue to a lysine (E1073K), was found in a patient with nMFS. ${ }^{122}$

The Shprintzen-Goldberg syndrome (SGS) is a disorder characterised by craniosynostosis and a marfanoid habitus with a range of other features including tall stature, arachnodactyly, dolichocephaly, pectus deformities, scoliosis, joint hypermobility, mental retardation, and more rarely, aortic root dilatation and mitral valve prolapse. ${ }^{132} \mathrm{~A}$ de novo FBN1 mutation (C1223Y) was found in a patient with sporadic disease, ${ }^{133}$ and a second change (P1148A) initially reported to be a mutation was later shown to be a polymorphic variant rather than a disease-causing mutation. ${ }^{134}{ }^{135}$ It is unknown if mutations in the fibrillin-1 gene are present in most cases of SGS, or if mutations in the fibrillin-1 gene merely contribute to the SGS phenotype in some cases, or whether any true association exists at all.

Autosomal dominant Weill-Marchesani syndrome has been linked to the region on chromosome 15 that contains FBN1. ${ }^{136}$ Fibrillin immunofluorescence abnormalities were also noted. Patients with Weill-Marchesani syndrome have ectopia lentis, but unlike patients with MFS, are of short stature.

Two FBN1 mutations have been identified in families with marfanoid phenotypes characterised only by skeletal abnormalities. The first (R2726W in exon 64) is predicted to substitute tryptophan for arginine at a site immediately adjacent to a consensus sequence for proteolytic cleavage. The mutation apparently abolished the proteolytic processing of the mutant monomers, which were not incorporated into the ECM. This may provide an explanation for the relatively mild phenotype of the affected family, since the cellular effect of the mutation may thus be equivalent to a "null" allele not expected to exert dominant negative effects. ${ }^{33}$ The second mutation ${ }^{137}$ affects a nonconserved residue in the cbEGF module encoded by exon $28(\mathrm{R} 1170 \mathrm{H})$ and is of as yet unknown significance. $\mathrm{R} 1170 \mathrm{H}$ has recently been described in a second family with skeletal manifestations and mitral valve prolapse. ${ }^{138}$

The mutation G1127S in FBN1 exon 27 was found in a family in whom ascending aortic disease had been identified in 10 members, nine of whom were shown to carry the mutation. None of them had classical MFS or typical signs such as scoliosis, pectus deformity, arachnodactyly, or ectopia lentis. Although exon 27 encodes a cbEGF module, the residue affected by the mutation G1127S has no known significance for calcium binding. ${ }^{139}$ NMR analysis of a chemically synthesised peptide consisting of fibrillin cbEGF modules 13 and 14 (exons 27 and 28) with either the wild type sequence or the mutation G1127S showed misfolding restricted to module $13 .{ }^{140}$ Two further mutations have been reported in patients with isolated thoracic aortic aneurysms, ${ }^{141}$ but not all families with autosomal dominant inheritance of thoracic aortic aneurysms show linkage to $F B N 1{ }^{142}$

In summary, the mutation data published to date have shown the existence of a hot spot for nMFS in exons 24-27 and 31-32, and that exon skipping mutations tend to be associated with a severe phenotype. The mutations identified in families with variant phenotypes have not allowed generalisations on the relationships between fibrillin pathogenesis and clinical disease. It is to be hoped that the international databank for FBN1 mutations will contribute to the understanding of FBN1 genotype-phenotype correlations in the future. ${ }^{117}$

\section{Fibrillin-2 mutations in CCA and other phenotypes}

Congenital contractural arachnodactyly (CCA) is an autosomal dominant disorder characterised by a marfanoid habitus, arachnodactyly, camptodactyly, crumpled ears, and mild contractures in the elbows, knees, and hips, as well as mild muscle hypoplasia especially of the calf muscles. ${ }^{143}$ During the quest to identify the genetic basis of MFS, a second fibrillin gene was fortuitously discov- 
ered. This second gene was mapped to chromosome 5 (5q23-31) and is now referred to as FBN2. CCA became a good candidate for linkage since its phenotype overlaps that of MFS. Linkage of FBN2 to CCA was indeed confirmed, ${ }^{17}{ }^{130}$ and several mutations have been identified in patients with CCA. ${ }^{144-149}$

Analysis of the nine FBN2 mutations published so far allows for some interesting speculation. All nine mutations are located between exons 24 and 34, analogous to the so called neonatal region of fibrillin-1. It can be hypothesised that this region plays a critical role during development. ${ }^{148}$

Mosaicism has also been observed in several patients with CCA. ${ }^{145146148}$ In one case, it appears that the fact that the subject was a mosaic helped to minimise the effect of the mutant allele. ${ }^{146}$ Like the gamut of severity observed in MFS and fibrillin-1 microfibrillopathies, a spectrum of CCA phenotypes also exists. A small number of case reports have described a severe/lethal form of CCA. Molecular studies of one such case has shown that the skipping of exon 34 of FBN2 causes this severe phenotype. ${ }^{146}$ Comparison of the cardiovascular features between severe/lethal CCA and MFS shows that the changes in the severe form of CCA are consistent with developmental abnormalities, namely septal defects, interrupted aortic arch, and a single umbilical artery. Gastrointestinal abnormalities consisting of duodenal and oesophageal atresia and intestinal malrotation were also seen in some cases of severe/lethal CCA. These developmental abnormalities are consistent with the postulated role of the two fibrillins.

It remains to be seen whether mutations in FBN2 outside the "neonatal region" cause phenotypes that are part of the spectrum of Marfan-like disease. Familial and some sporadic cases of cardiac septal defect, for example, make interesting candidates for continued molecular analysis.

\section{LTBP mutations}

Evolutionary comparisons have placed LTBP-2 as the LTBP most closely related to the fibrillins. Therefore, it was hypothesised that mutations in $L T B P-2$, as well as other components of the extracellular matrix microfibrils, may cause disorders whose phenotypes overlap those of MFS. Since abnormal fibrillin immunofluorescence may be found in disorders caused by defects in both FBN1 and FBN2, ${ }^{16} 128146$ the possibility that similar abnormalities would be observed in subjects with $L T B P-2$ mutations was considered. Preliminary studies have shown at least one putative mutation in a patient and his mother with pectus deformities (Mathews and Godfrey, unpublished data). This amino acid substitution is in a highly conserved region in a cbEGF domain and analogous substitutions in FBN1 have been documented in nMFS and ectopia lentis.
Fibrillin mRNA expression and the dominant negative pathogenesis of Marfan syndrome

mRNAs which carry a premature termination codon (PTC) owing to either a frameshift or a nonsense mutation are usually present in reduced concentration. As a general rule, the closer a PTC codon occurs after the initiation codon, the more likely it is that the mutant mRNA will be reduced in abundance. ${ }^{150}$ Several PTC mutations in the fibrillin-1 gene have been characterised as having reduced mRNA expression. ${ }^{120}{ }^{122}{ }^{151}$ A 4 bp deletion in exon 41 was identified in a patient with the so called MASS phenotype (Myopia, Mitral valve prolapse, mild Aortic root dilatation without dissection, Skin abnormalities (striae), and Skeletal involvement). The mutant mRNA was expressed at a level of $6 \%$ of the normal allele. ${ }^{151}$ In contrast, a mutation leading to skipping of exon 2 (83 bp) with frameshift and PTC was associated with classical MFS; in this case, the mutant mRNA was expressed at a level of $16 \%$ of the normal allele. ${ }^{151}$ The authors concluded that the reduced expression of the mutant peptide leads to a preponderance of normal fibrillin monomers in the polymeric microfibrils, so that below a certain threshold of expression, there is mild disease. On the other hand, if a certain threshold is crossed (between 6 and $16 \%$ of wild type levels), the mutant, C-terminally truncated peptide disturbs the polymeric structure to such an extent that more severe disease is seen. It also suggests that the $\mathrm{N}$-terminal region of fibrillin may be crucial for microfibrillar assembly and that it is able to interact in a dominant negative manner with the wild type monomer. ${ }^{151}$ According to the dominant negative model of pathogenesis, ${ }^{152}$ the product of the mutant allele interferes with the function of the wild type allele. In the case of the MFS, this model seems particularly attractive, because fibrillin monomers aggregate in large, multimeric structures in the course of the formation of microfibrils. Mutant monomers would then disturb the function of the multimeric microfibrils.

\section{Calcium binding and mutations in cbEGF motifs}

Epidermal growth factor-like (EGF) modules are approximately 45 amino acid residues long and contain six conserved cysteine residues that are paired to form disulphide bonds in a characteristic manner ( 1 to 3,2 to 4 , and 5 to 6 ). In addition to the three disulphide bonds, EGF modules are characterised by a double stranded beta sheet as a main structural feature. A subset of EGF modules also contains a consensus sequence for calcium binding (cbEGF), X-D/N$\mathrm{X}-\mathrm{D} / \mathrm{N}-\mathrm{E} / \mathrm{Q}-\mathrm{C}_{1}$, comprising the first five residues before the first cysteine residue $\left(C_{1}\right)$ in the context of an EGF residue, which also shows a consensus sequence for $\beta$-hydroxylation between the third and fourth cysteine residues: $\mathrm{C}_{3}-\mathrm{X}-(\mathrm{D} / \mathrm{N})-\mathrm{X}-\mathrm{X}-\mathrm{X}-\mathrm{X}-(\mathrm{F} / \mathrm{Y})-\mathrm{X}-\mathrm{C}_{4}{ }^{24}{ }^{2153-155}$ In these consensus sequences, $\mathrm{X}$ is used to refer to any amino acid, but a non-random distribution of amino acids (three to six at any given position) was found in a sequence alignment of 154 
EGF-like domains, which suggests that these positions are important for calcium binding. ${ }^{155}$ Including the above consensus sequences and the six cysteine residues, 19 of the on average 42 residues of each cbEGF module of fibrillin-1 are predicted to play an important role in calcium binding (fig 2).

Native fibrillin binds calcium, ${ }^{156}$ but there appear to be significant variations in the calcium binding affinity among different cbEGF modules along the length of fibrillin-1, such that some cbEGF modules may be only partially saturated with calcium under physiological conditions. ${ }^{157}$ It is conceivable that partially saturated domains may be more flexible than higher affinity domains. ${ }^{157} \mathrm{Cal}-$ cium coordination is thought to be mediated by a pentagonal, bipyrimidal structure, with the residues of the calcium binding consensus sequence either providing direct oxygen or carbonyl ligands, or playing a role in the stabilisation of the calcium binding site. ${ }^{158}$ Binding of calcium by one cbEGF module can be influenced by calcium binding to other tandem cbEGF modules, such that the binding affinity is significantly increased. ${ }^{159}$

Although NMR analysis of a pair of cbEGF modules from fibrillin-1 showed that no ligand is donated from one cbEGF module to the next, ${ }^{160}$ as is the case with the two cbEGF modules of factor IX, ${ }^{158}$ calcium binding does appear to rigidify the interdomain region between two cbEGF repeats, ${ }^{160} 161$ which in turn enables multiple tandem cbEGF repeats to take on a rigid, rod-like conformation. ${ }^{162}$ Removal of calcium by incubation in EDTA leads to a reversible disruption of microfibrillar structure, in which the region between the beads takes on a frayed appearance under elec-

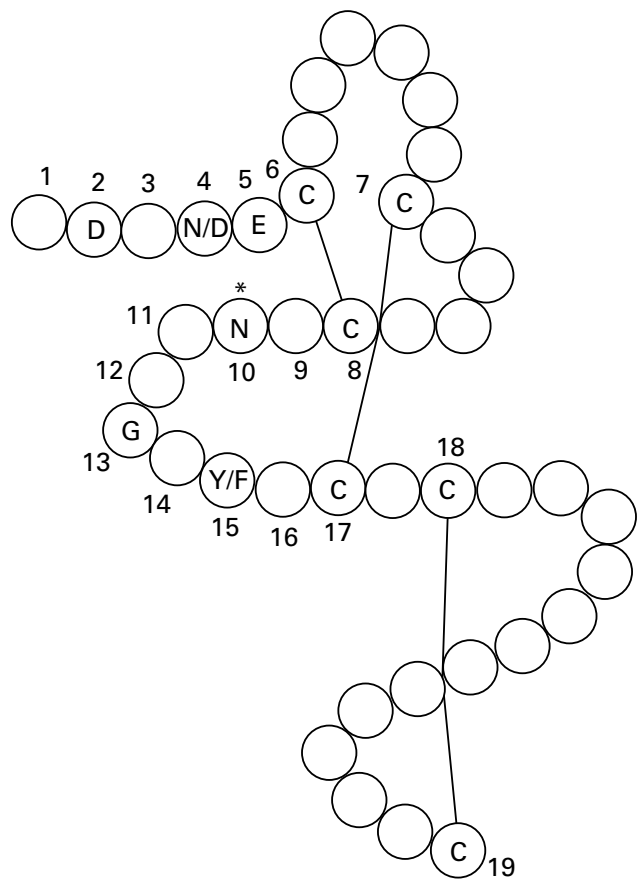

Figure 2 A calcium binding epidermal growth factor-like motif (cbEGF). The positions marked with the numbers 1 to 19 comprise the six highly conserved cysteine residues as well as the consensus calcium binding sequence, which in turn contains a consensus sequence for $\beta$ hydroxylation (see text). tron microscopy. ${ }^{163}$ This suggests that domains $\mathrm{B}$ and $\mathrm{D}$ (which contain all of the cbEGF modules of fibrillin-1 and -2) are located in the interbead region. Electron microscopic analysis of a recombinant fibrillin fragment containing a stretch of 12 uninterrupted cbEGF modules found in region $\mathrm{D}$ suggested that calcium binding causes the stretch of cbEGF modules to assume a stabilised, more extended, and rigid conformation. ${ }^{164}$ Tandemly repeated EGF modules are a common motif of proteins of the ECM, such as laminin, thrombospondin, and tenascin, and form extended, rod-like domains essential for the global structure of these proteins. ${ }^{165}$ In contrast, the interdomain linkage between an N-terminal LTBP module and a C-terminal cbEGF module may be significantly more flexible. ${ }^{166}$ In addition to the structural functions of EGF modules described above, EGF modules have been shown to mediate calcium dependent protein-protein interactions. ${ }^{167}$ At present, it is not known if the cbEGF-like modules of the fibrillins are able to mediate protein-protein interactions.

Calcium binding stabilises fibrillin-1 against proteolytic degradation, which emphasises the importance of calcium binding for the structural integrity of fibrillin-1. Similar findings have been observed in other proteins of the ECM, such as fibulin-1 and fibulin-2, ${ }^{168}$ LTBP- $1,{ }^{169}$ LTBP- $2,{ }^{58}$ as well as bovine protein C. ${ }^{170}$ Fibrillin molecules and fibrillin containing microfibrils can be degraded by serine proteinases $^{171}$ and matrix metalloproteinases (MMP) ${ }^{172}$ It is conceivable that some fibrillin-1 mutations may increase the proteolytic degradation of microfibrils in tissue, in turn leading to abnormal microfibril morphology and function.

Calcium binding EGF modules (cbEGF) are found in many different proteins, including numerous proteins of the ECM (laminin, thrombospondin, fibrillin-1 and -2, the LTBPs, fibulin-1, and -2, nidogen), blood coagulation factors (factor IX, X, proteins C and S), and proteins involved in specification of cell fate (Drosophila Notch, Delta, Serrate). Disease-causing mutations in cbEGF modules leading to reduced calcium binding have been identified not only in MFS but also in several other disorders including haemophilia B. ${ }^{173}$

Mutations affecting residues of the calcium binding consensus sequence can reduce calcium affinity, as has been shown experimentally with a chemically synthesised peptide containing a mutation (N2144S) of a residue of the calcium binding consensus sequence of the cbEGF module encoded by exon $52 .{ }^{174}$ In addition, rotary shadowing of fibrillincontaining microfibrils from the patient carrying the mutation $\mathrm{N} 2144 \mathrm{~S}$ showed a frayed appearance of the interbead region, ${ }^{174}$ as was true for another mutation in the same exon (D2127E), which affects a different residue of the calcium binding consensus sequence. ${ }^{114}$

A classification of cbEGF mutations according to their effects on structure and function has been proposed. ${ }^{160}$ Mutations of one of the six conserved cysteine residues probably cause domain misfolding, which may also have 
deleterious effects on the global structure of fibrillin. Alterations of residues of the calcium binding consensus sequence may result in reduced calcium affinity, which may in turn destabilise the interface between two consecutive cbEGF domains. Mutations not affecting cysteine residues or the calcium binding consensus sequence may have effects on intraor intermolecular interactions; a mutation (G2627R) of the glycine involved in domaindomain packing between two cbEGF modules ${ }^{160}$ is predicted to alter the pairwise interaction of the adjacent cbEGF modules. Finally, other mutations which do not alter residues with obvious structural relevance may conceivably be involved in protein-protein interactions. ${ }^{160}$

\section{Immunohistochemical abnormalities of microfibrils in Marfan syndrome} Indirect immunofluorescence with monoclonal antibodies against fibrillin displays a characteristic immunostaining pattern in skin specimens from healthy controls. The dermal-epidermal junction appears as a bright and nearly continuous band parallel to the basement membrane, below which linear strands of fibres descend. The papillary dermis displays a branching meshwork of fibres of various diameters, whereas deeper in the reticular dermis, thicker undulating fibres of various lengths and diameters predominate. Most microfibrillar fibres in this region are associated with elastin. Many, but not all patients with MFS display qualitative and quantitative abnormalities of the dermal microfibrillar network. ${ }^{16}$ Immunofluorescent abnormalities are also present in cardiovascular tissues affected by MFS, such as the aortic valve, the ascending aortic wall, and the mitral valve. ${ }^{176}$

Immunofluorescent investigations cannot be used as the sole diagnostic test, since patients with other connective tissue disorders can also show abnormalities of the microfibrillar network when examined by this method (see also the hypothesis for the LTBP-2 studies). Additionally, up to $35 \%$ of all patients suspected of having MFS may display an apparently normal fibrillin immunostaining pattern in skin specimens. ${ }^{16}$ Immunostaining in some older unaffected subjects (>70 years) may appear abnormal.

The microfibrillar network of dermal fibroblast cultures can also be investigated by fibrillin immunofluorescence. In most cases, MFS patients show reduced staining intensity indicating a deficient accumulation of reactive fibrous materials. In most MFS patients, there is a reduced staining intensity in both skin samples and dermal fibroblast cultures, but in about $30 \%$ of patients, the apparent content of microfibrillar fibres in the skin is normal or near normal, while fibroblast cultures show clearly decreased accumulations of fibrous materials. Rarely, the converse is true, and even more rarely, a patient with classical features of MFS will have apparently normal results for both investigations. These abnormalities cosegregate with the Marfan phenotype within families. ${ }^{177}$
Therefore, fibrillin immunofluorescence has neither sufficient specificity nor sensitivity to be used as a routine diagnostic tool. It is important to note, however, that normal skin and fibroblast culture fibrillin immunofluorescence patterns are almost never seen in patients with MFS. Thus, normal findings in both assays make the likelihood of MFS very low.

\section{Metabolic labelling of fibrillin:} investigation of fibrillin synthesis, secretion, and deposition in the extracellular matrix

A cell culture approach has been developed to investigate the synthesis and assembly of fibrillin in vivo. Owing to its high content of cysteine residues (ca 14\%), fibrillin can be labelled with radioactive $\left[{ }^{35} \mathrm{~S}\right]$ cysteine and isolated by immunoprecipitation. Protocols have been developed to separate the cell fraction, the medium, and the ECM fraction, which is defined as the material remaining on the surface of the culture vessel after the harvesting of the other fractions. With this system, information can be gained about the synthesis and secretion of fibrillin as well as on its deposition into the ECM and its aggregation into multimeric structures. ${ }^{178}$ The biochemical phenotype defined by these parameters is almost always constant among the affected relatives with MFS. ${ }^{179}$

The glycoprotein fibrillin is synthesised as a $350 \mathrm{kDa}$ propeptide, profibrillin, which is secreted out of the cell within four to eight hours. Profibrillin is cleaved in the extracellular space to fibrillin, which has an apparent molecular weight of $320 \mathrm{kDa} .{ }^{33}$ The conversion of profibrillin to fibrillin is calcium dependent. ${ }^{115}$ Fibrillin monomers are then deposited into the ECM where the formation of large, insoluble aggregates takes place. Most of the deposition of fibrillin occurs within the first eight hours after the pulse. ${ }^{179}$ Fibrillin is assembled into high $M_{r}$ disulphide bonded aggregates; the formation of aggregates appears to begin in the medium fraction. ${ }^{178}$

MFS patients show a variety of abnormalities in this system, including decreased synthesis, delayed secretion, and reduced deposition into the ECM; some patients display no abnormalities detectable with this methodology. ${ }^{179}$

Defined classes of mutation may have specific effects on fibrillin metabolism in this assay. Mutations of cysteine residues were shown to be associated in most cases with delayed secretion of fibrillin presumed to be because of improper protein folding caused by a disruption of disulphide bonding within the affected domain. ${ }^{180}$ Delayed secretion may in turn be associated with other abnormalities. For instance, a nonsense mutation in the last $F B N 1$ exon was shown to cause delayed secretion with resultant over- $N$-glycosylation of fibrillin. ${ }^{37}$ It is not known, however, if over-N glycosylation per se causes functional impairments.

Using metabolic labelling of dermal fibroblast cultures from patients with MFS, Aoyama et $a l^{181}$ developed a five group classification of the biochemical phenotype as defined by the parameters of fibrillin synthesis and ECM 
deposition. ${ }^{181}$ The FBN1 mutation had been identified in 13 of the 55 investigated cell lines, so that hypotheses concerning correlations between genotype and biochemical phenotype could be made.

Groups I and II were characterised by reduced fibrillin synthesis; group II additionally showed impaired ECM deposition. Mutations found in these groups were either nonsense or frameshift mutations and were associated with reduced mRNA expression. The mutations found in group II showed relatively higher levels of mRNA expression (16-25\%). Since the ECM deposition was also significantly impaired in group II, it is conceivable that a relatively greater amount of C-terminally truncated fibrillin in class II was able to impair the deposition of the normal fibrillin protein product in a dominant negative manner.

Groups III and IV both showed normal levels of fibrillin synthesis; group III showed a slight impairment of fibrillin ECM deposition, and group IV showed a severe impairment. All the mutations identified in these groups were missense mutations; while the pathogenesis involved in group IV appeared to be related to dominant negative inhibition of microfibril assembly, the pathogenetic mechanisms of group III seemed to be more heterogeneous. Interestingly, cell lines in group $\mathrm{V}$ displayed normal fibrillin synthesis, secretion, and ECM deposition. It remains speculative whether functional defects of fibrillin or microfibrils will eventually be shown for this group.

The classification into five groups has a prognostic significance; the incidence of aortic dissection was found to be higher in patients from groups II and IV (with a postulated dominant negative pathogenesis) than in groups I and III. ${ }^{182}$

Although most cell lines can be classified according to the above scheme, the range of biochemical phenotypes may be more complex than merely five groups. One patient with a missense mutation affecting a cysteine residue in the cbEGF module encoded by exon 14 showed normal synthesis and ECM deposition associated with delayed secretion. ${ }^{183}$ The patient was mildly affected, in contrast to an earlier observation that patients with delayed secretion tend to have the most severe phenotypes. ${ }^{179}$

\section{Electron microscopic abnormalities of microfibrils in MFS}

Electron microscopic examination of fibrillinassociated microfibrils shows a string of globular structures joined by fine filaments, giving the appearance of "beads on a string". The string has a diameter of 10 to $12 \mathrm{~nm}$, the beads of up to $22 \mathrm{~nm}$. Strings with up to 60 beads can be seen by electron microscopy. The beads show a variable periodicity which significantly increases when the tissue extract is subjected to tension; the $52 \mathrm{~nm}$ periodicity shown in standard biopsy specimens probably represents the period present in relaxed tissue specimens. ${ }^{65}$

Taken together, there are four types of electron microscopically visible abnormalities of microfibrils isolated from dermal fibroblast cultures from MFS patients: (1) complete or nearly complete lack of microfibrillar assemblies; (2) poorly defined interbead domains with normal periodicity and morphology of the beads; (3) a "frayed" appearance of the interbead domains; and (4) variable interbead periodicity. ${ }^{114} 115184185$

Although no systematic studies have been published, results published to date suggest there may be a loose correlation between electron microscopic morphology and degree of clinical severity in some cases. For instance, two patients with autosomal dominant ectopia lentis without cardiovascular involvement showed abnormalities of class 3 or $4,{ }^{185}$ whereas one severely affected MFS patient showed abnormalities of class $1 .{ }^{114}$

It is important to keep in mind that these electron microscopy abnormalities are true only in secreted, rotary shadowed fibrils. Examination of skin from numerous MFS patients using transmission electron microscopy has shown microfibrils of normal morphology. No quantitative (electron microscopy is a poor tool for quantitation) or qualitative changes have been found (Keene, Godfrey, and Hollister, unpublished data).

\section{Animal models of the Marfan syndrome}

Animal models for human disease can be useful to understand the pathogenesis or to explore novel treatment modalities. The first reported naturally occurring model for Marfan syndrome was a cow with skeletal, ocular, and cardiovascular features resembling those seen in the human disease. The phenotype was passed on from an apparently germline mosaic bull to several calves. Light microscopy of the aorta showed typical elastic abnormalities that are seen in the Marfan syndrome. ${ }^{186}{ }^{187}$ Both fibrillin immunostaining and metabolic labelling were abnormal and similar to what is seen in human Marfan syndrome. ${ }^{188}$ Unfortunately, to date no bovine FBN1 mutation has been reported in this herd.

Periera et $a l^{189}$ have reported gene targeting experiments in a murine model that recapitulates the vascular abnormalities of the human disease. They deleted exons 19 to 24 (which included a portion of the so called neonatal region) of $F B N 1$. Mice that were heterozygous for the targeted mutation were morphologically and histologically normal and indistinguishable from wild type mice. They lived normal life spans and were fertile. Mice that harboured both targeted alleles (homozygous mutants) had greatly reduced life spans, abnormal fibrillin immunofluorescence and metabolic labelling profiles, and aortic disease similar to that seen in human Marfan syndrome.

The only known naturally occurring fibrillin-1 gene mutation in mice is a tandem duplication of fibrillin-1 in the Tight skin mouse (Tsk). ${ }^{190}$ This mouse is heterozygous for a genomic duplication of some 30 to $40 \mathrm{~kb}$ encompassing exons 17 to 40 of FBN1. The Tsk/+ mouse has thickened skin and visceral fibrosis that results from an accumulation of extracellular matrix molecules. Thus, the 
Tsk/+ mouse has become a model for scleroderma, hereditary emphysema, and myocardial hypertrophy. Tsk/Tsk homozygous embryos do not live past day 8 of development. Interestingly, the mutant fibrillin-1 assembles into abnormal microfibrils with increased interbead distances and aggregated clusters, ${ }^{110}$ not found in wild type mice. There is to date no recognised human equivalent of the Tight skin mouse.

\section{Conclusions}

Since the discovery of fibrillin in 1986 by Sakai et $a l,{ }^{15}$ significant progress has been made in the understanding of fibrillin physiology and pathophysiology. From the identification of the first FBN1 mutation in 1991 by Dietz et $a l^{20}$ to the present, a total of $137 \mathrm{FBN} 1$ mutations have been reported to the international database. FBN1 mutations have been shown to be associated not only with Marfan syndrome, but also with a wide range of connective tissue disorders termed type 1 fibrillinopathies. Mutations have also been found in the closely related fibrillin-2 gene in patients with congenital contractural arachnodactyly, and it appears that disease causing mutations will be found in the future in other genes whose products are involved in microfibril metabolism, such as LTBP-2. Therefore, Marfan syndrome is just one of a group of clinical disorders, which may be termed "microfibrillopathies".

One of the most interesting topics in the field revolves around the pathophysiological mechanisms whereby fibrillin-1 mutations lead to clinical disease. Do most mutations lead to a more or less global disturbance of fibrillin function with differing degrees of severity? Do mutations associated with milder type 1 fibrillinopathies, such as dominant ectopia lentis, affect only certain functions of fibrillin in a specific manner? Do genotype-phenotype correlations exist for classical Marfan syndrome, which could explain the observation that a family history of severe MFS related cardiac disease is associated with an increased risk of aortic complications in families with Marfan syndrome? Answers to these questions will require much more mutation data together with detailed clinical evaluation of the patients and their families. The international FBN1 mutation data bank ${ }^{117}$ should prove useful in this regard. Progress in the understanding of fibrillin pathophysiology obviously is dependent on advances in research on fibrillin and microfibril physiology. Key questions involve the mechanisms surrounding the polymerisation of fibrillin monomers and other proteins into microfibrils and the nature of the interactions between the microfibrils and other components of the extracellular matrix. The differential expression of the various microfibrillar components during development and between different tissues is just beginning to be unravelled.

Gene therapy for patients with Marfan syndrome is not likely to become reality in the near future. Since a dominant negative mechanism of pathogenesis is assumed to be significant for most cases of MFS, gene therapy for
MFS will probably involve the down regulation of the mutant allele by one of a number of methods. Since haploinsufficiency or extreme reduction of the mutant allele may also lead to clinical disorders such as the MASS syndrome, it may be desirable to combine down regulation of the mutant allele (or both endogeneous alleles) with the delivery and expression of normal fibrillin under appropriate regulatory control. Initial experiments suggest that at least the first goal may be reachable; approaches using ribozymes with a sequence complementary to fibrillin mRNA led to specific cleavage of fibrillin mRNA with a corresponding drop in expression of fibrillin protein by transfected cells. ${ }^{191} 192$ Although the ribozymes used in these experiments were targeted to wild type fibrillin-1 sequences, it is also possible to target at least some mutations in a specific manner. ${ }^{193}$

Marfan syndrome is a clinical diagnosis and will probably remain so for the foreseeable future. The great majority of FBN1 mutations identified to date are unique, and there is generally no way of predicting the clinical severity or of understanding whatever genotypephenotype correlation there may be at a molecular level. The full spectrum of the microfibrillopathies remains to be defined. Nevertheless, the enormous progress made in the last decade and the ever growing scientific interest in Marfan syndrome and the extracellular microfibrils leads one to expect that basic research and perhaps also clinical applications will continue to progress by leaps and bounds.

P N Robinson would like thank Gerhard Gaedicke, Andreas Kulozik, and Christian Hagemeier for their friendly support. This work was supported by a grant from the Deutsche Forschungsgemeinschaft (Ro 2005/2-1). MG is an Established Investigator of the American Heart Association (funding was contributed in part by the AHA Florida Affiliate)

1 Pyeritz RE. The Marfan syndrome. In: Steinmann B, ed. Connective tissue and its heritable disorders. New York: WileyLiss, 1993:437-68.

2 Gray JR, Davies SJ. Marfan syndrome. 7 Med Genet 1996;33:403-8.

3 Gray JR, Bridges AB, Faed MJ, et al. Ascertainment and Gray JR, Bridges AB, Faed MJ, et al. Ascertainment and
severity of Marfan syndrome in a Scottish population. $\mathcal{J}$ Med Genet 1994;31:51-4.

4 Sponseller PD, Hobbs W, Riley LH III, Pyeritz RE. The thoracolumbar spine in Marfan syndrome. $\mathcal{F}$ Bone foint Surg 1995;77:867-76.

5 Arn PH, Scherer LR, Haller JA Jr, Pyeritz RE. Outcome of pectus excavatum in patients with Marfan syndrome and in the general population. I Pediatr 1989;115:954-8.

6 Cross HE, Jensen AD. Ocular manifestations in the Marfan syndrome and homocystinuria. Am f Ophthalmol 1973;75: 405-20

7 Roman MJ, Rosen SE, Kramer-Fox R, Devereux RB. Prognostic significance of the pattern of aortic root dilation in the Marfan syndrome. 7 Am Coll Cardiol 1993;22:1470-6.

8 Silverman DI, Gray J, Roman MJ, et al. Family history of severe cardiovascular disease in Marfan syndrome is associated with increased aortic diameter and decreased survival. $\mathcal{F}$ Am Coll Cardiol 1995;26:1062-7.

9 Silverman DI, Burton KJ, Gray J, et al. Life expectancy in Silverman DI, Burton KJ, Gray J, et al. Life expectancy
the Marfan syndrome. Am f Cardiol 1995;75:157-60.

10 Gott VL, Laschinger JC, Cameron DE, et al. The Marfan syndrome and the cardiovascular surgeon. Eur $\mathcal{F}$ Cardiothorac Surg 1996;10:149-58.

11 Shores J, Berger KR, Murphy EA, Pyeritz RE. Progression of aortic dilatation and the benefit of long-term $\beta$-adrenergic blockade in Marfan's syndrome. $N$ Engl $f$ Med 1994;330:1335-41.

12 Salim MA, Alpert BS, Ward JC, Pyeritz RE. Effect of betaadrenergic blockade on aortic root rate of dilation in the Marfan syndrome. Am f Cardiol 1994;74:629-33.

13 De Paepe A, Devereux RB, Dietz HC, Hennekam RC, Pyeritz RE. Revised diagnostic criteria for the Marfan syndrome. Am 7 Med Genet 1996;62:417-26.

14 Lipscomb KJ, Clayton-Smith J, Harris R. Evolving phenotype of Marfan's syndrome. Arch Dis Child 1997;76:41-6.

15 Sakai LY, Keene DR, Engvall E. Fibrillin, a new 350-kD glycoprotein, is a component of extracellular microfibrils. $\mathcal{F}$ Cell Biol 1986;103:2499-509. 
16 Hollister DW, Godfrey M, Sakai LY, Pyeritz RE. Immunohistologic abnormalities of the microfibrillar-fiber system in the Marfan syndrome. N Engl f Med 1990;323:152-9.

17 Lee B, Godfrey M, Vitale E, et al. Linkage of Marfan syndrome and a phenotypically related disorder to two different fibrillin genes. Nature 1991;352:330-4

18 Kainulainen K, Pulkkinen L, Savolainen A, Kaitila I, Peltonen L. Location on chromosome 15 of the gene defect causing Marfan syndrome. N Engl f Med 1990;323:935-9.

19 Kainulainen K, Steinmann B, Collins F, et al. Marfan syndrome: no evidence for heterogeneity in different populations, and more precise mapping of the gene. Am f Hum lations, and more pre

20 Dietz HC, Cutting GR, Pyeritz RE, et al. Marfan syndrome caused by a recurrent de novo missense mutation in the fibrillin gene. Nature 1991;352:337-9.

21 Biery NJ, Eldadah ZA, Moore CS, Stetten G, Spencer F, Dietz HC. Revised genomic organization of FBN1 and sig70-7.

22 Pereira L, D'Alessio M, Ramirez F, et al. Genomic organization of the sequence coding for fibrillin, the defective gene product in Marfan syndrome. Hum Mol Genet 1993;2: product

23 Sakai LY, Keene DR, Glanville RW, Bachinger HP. Purification and partial characterization of fibrillin, a cysteine-rich structural component of connective tissue microfibrils. $\mathcal{F}$ Biol Chem 1991;266:14763-70

24 Handford PA, Mayhew M, Baron M, Winship PR, Campbell ID, Brownlee GG. Key residues involved in calcium-binding motifs in EGF-like domains. Nature 1991; 351:164-7.

25 Yuan X, Downing AK, Knott V, Handford PA. Solution structure of the transforming growth factor $\beta$-binding protein-like module, a domain associated with matrix protein-like module, a domain

26 Hynes RO. Integrins: versatility, modulation, and signaling in cell adhesion. Cell 1992;69:11-25.

27 Pfaff M, Reinhardt DP, Sakai LY, Timpl R. Cell adhesion and integrin binding to recombinant human fibrillin-1. FEBS Lett 1996;384:247-50

28 Sakamoto H, Broekelmann T, Cheresh DA, Ramirez F, Rosenbloom J, Mecham RP. Cell-type specific recognition of RGD- and non-RGD-containing cell binding domains in fibrillin-1. F Biol Chem 1996;271:4916-22.

29 D'Arrigo C, Burl S, Withers AP, Dobson H, Black C, Boxer $M$. TGF- $\beta 1$ binding protein-like modules of fibrillin- 1 and -2 mediate integrin-dependent cell adhesion. Connect -2
Tissue Res $1998 ; 37: 29-51$.

30 Reinhardt DP, Keene DR, Corson GM, et al. Fibrillin-1 organization in microfibrils and structural properties. $\mathcal{F ~ M o l}$ Biol 1996;258:104-16.

31 Yin W, Smiley E, Germiller J, et al. Primary structure and developmental expression of Fbn-1, the mouse fibrillin gene. F Biol Chem 1995;270:1798-806.

32 Zhang H, Apfelroth SD, Hu W, et al. Structure and expression of fibrillin-2, a novel microfibrillar component preferentially located in elastic matrices. F Cell Biol 1994;124: 855-63.

33 Milewicz DM, Grossfield J, Cao SN, Kielty C, Covitz W, Jewett T. A mutation in FBN1 disrupts profibrillin processJewett T. A mutation in FBN1 disrupts profibrillin processing and results in isolated skeletal features

34 Raghunath M, Putnam EA, Ritty T, et al. Carboxy-terminal conversion of profibrillin to fibrillin at a basic site by $\mathrm{PACE} /$ furin-like activity required for incorporation in the matrix. F Cell Sci 1999;112:1093-100

35 Lönnqvist L, Reinhardt D, Sakai L, Peltonen L. Evidence for furin-type activity-mediated C-terminal processing of profibrilin-1 and interference in the processing by certai mutations. Hum Mol Genet 1998; 7:2039-44.

36 Ritty TM, Broekelmann T, Tisdale C, Milewicz DM, Mecham RP. Processing of the fibrillin-1 carboxyl-terminal Mecham RP. Processing of the fibrillin-1
domain. F Biol Chem 1999;274:8933-40.

37 Raghunath M, Kielty CM, Steinmann B. Truncated profibrillin of a Marfan patient is of apparent similar size as fibrillin: intracellular retention leads to over-Nglycosylation. f Mol Biol 1995;248:901-9.

38 Glanville RW, Qian RQ, McClure DW, Maslen CL. Calcium binding, hydroxylation, and glycosylation of the precursor epidermal growth factor-like domains of 26630-4

39 Zhang H, Hu W, Ramirez F. Developmental expression of fibrillin genes suggests heterogeneity of extracellular microfibrils. F Cell Biol 1995;129:1165-76.

40 Rongish BJ, Drake CJ, Argraves WS, Little CD. Identification of the developmental marker, JB3-antigen, as fibrillin-2 and its de novo organization into embryonic microfibrous arrays. Dev Dyn 1998;212:461-71.

41 Boileau C, Jondeau G, Babron MC, et al. Autosomal dominant Marfan-like connective-tissue disorder with aortic dilation and skeletal anomalies not linked to the fibrillin genes. Am F Hum Genet 1993;53:46-54.

42 Collod G, Babron MC, Jondeau G, et al. A second locus for Marfan syndrome maps to chromosome 3p24.2-p25. Nat Genet 1994;8:264-8.

43 Dietz H, Francke U, Furthmayr H, et al. The question of heterogeneity in Marfan syndrome. Nat Genet 1995;9:22831

44 Ramirez F. Fibrillin mutations in Marfan syndrome and related phenotypes. Curr Opin Genet Dev 1996;6:309-15.
45 Saharinen J, Taipale J, Keski-Oja J. Association of the small latent transforming growth factor- $\beta$ with an eight cysteine repeat of its binding protein LTBP-1. EMBO ₹ 1996;15: $245-53$.

46 Gleizes PE, Beavis RC, Mazzieri R, Shen B, Rifkin DB. Identification and characterization of an eight-cysteine repeat of the latent transforming growth factor- $\beta$ binding protein-1 that mediates bonding to the latent transforming growth factor- $\beta 1$. F Biol Chem 1996;271:29891-6.

47 Miyazono K, Olofsson A, Colosetti P, Heldin CH. A role of the latent TGF- $\beta 1$-binding protein in the assembly and secretion of TGF- $\beta 1$. EMBO ₹ 1991;10:1091-101.

48 Dallas SL, Miyazono K, Skerry TM, Mundy GR, Bonewald LF. Dual role for the latent transforming growth factor- $\beta$ binding protein in storage of latent TGF- $\beta$ in the extracellular matrix and as a structural matrix protein. $\mathcal{F}$ Cell Biol 1995;131:539-49.

49 Nakajima Y, Miyazono K, Kato M, Takase M, Yamagishi T, Nakamura $H$. Extracellular fibrillar structure of latent endothelial-mesenchymal transformation during endocarendothelial-mesenchymal transformation during endocarCell Biol 1997;136:193-204.

50 Hori Y, Katoh T, Hirakata M, et al. Anti-latent TGF- $\beta$ binding protein-1 antibody or synthetic oligopeptides inhibit extracellular matrix expression induced by stretch in cultured rat mesangial cells. Kidney Int 1998;53:1616-25.

51 Taipale J, Miyazono K, Heldin CH, Keski-Oja J. Latent transforming growth factor- $\beta 1$ associates to fibroblast extracellular matrix via latent TGF- $\beta$ binding protein. $\mathcal{f}$ Cell Biol 1994;124:171-81.

52 Karonen T, Jeskanen L, Keski-Oja J. Transforming growth factor $\beta 1$ and its latent form binding protein-1 associate with elastic fibres in human dermis: accumulation in actinic damage and absence in anetoderma. $\mathrm{Br} f$ Dermatol 1997; 137:51-8.

53 Flaumenhaft R, Abe M, Sato Y, et al. Role of the latent TGF- $\beta$ binding protein in the activation of latent TGF- $\beta$ by co-cultures of endothelial and smooth muscle cells. $\mathcal{F}$ Cell Biol 1993;120:995-1002.

54 Taipale J, Saharinen J, Hedman K, Keski-Oja J. Latent transforming growth factor- $\beta 1$ and its binding protein are components of extracellular matrix microfibrils. F Histochem Cytochem 1996;44:875-89.

55 Olofsson A, Ichijo H, Moren A, ten Dijke P, Miyazono K, Heldin $\mathrm{CH}$. Efficient association of an amino-terminally extended form of human latent transforming growth factor- $\beta$ binding protein with the extracellular matrix. $f$ Biol Chem 1995;270:31294-7.

56 Morén A, Olofsson A, Stenman G, et al. Identification and characterization of LTBP-2, a novel latent transforming 32469-78.

57 Gibson MA, Hatzinikolas G, Davis EC, Baker E, Sutherland GR, Mecham RP. Bovine latent transforming growth factor $\beta 1$-binding protein 2: molecular cloning, identification of tissue isoforms, and immunolocalization to elastinassociated microfibrils. Mol Cell Biol 1995;15:6932-42.

58 Hyytiäinen $M$, Taipale J, Heldin CH, Keski-Oja J. Recombinant latent transforming growth factor $\beta$-binding protein 2 assembles to fibroblast extracellular matrix and is susceptible to proteolytic processing and release. 7 Biol Chem 1998;273:20669-76.

59 Yin W, Smiley E, Germiller J, et al. Isolation of a novel latent 3) $\mathcal{F}$ Biol Chem $1995 ; 270: 10147-60$

60 Yin W, Fang J, Smiley E, Bonadio J. 8-Cysteine TGF-BP structural motifs are the site of covalent binding between mouse LTBP-3, LTBP-2, and latent TGF- 31 . Biochim Biophys Acta 1998;1383:340-50.

61 Giltay R, Kostka G, Timpl R. Sequence and expression of a novel member (LTBP-4) of the family of latent transforming growth factor- $\beta$ binding proteins. FEBS Lett 1997;411: 164-8.

62 Saharinen J, Taipale J, Monni O, Keski-Oja J. Identification and characterization of a new latent transforming growth factor- $\beta$-binding protein, LTBP-4. F Biol Chem 1998;273: 18459-69.

63 Rosenbloom J, Abrams WR, Mecham R. Extracellular matrix 4: the elastic fiber. FASEB f 1993;7:1208-18.

64 Raghunath M, Bachi T, Meuli M, et al. Fibrillin and elastin expression in skin regenerating from cultured keratinocyte autografts: morphogenesis of microfibrils begins at the dermo-epidermal junction and precedes elastic fiber formation. F Invest Dermatol 1996;106:1090-5.

65 Keene DR, Maddox BK, Ku HJ, Sakai LY, Glanville RW. Extraction of extendable beaded structures and their identification as fibrillin-containing extracellular matrix microfibrils. F Histochem Cytochem 1991;39:441-9.

66 Lillie MA, David GJ, Gosline JM. Mechanical role of elastin-associated microfibrils in pig aortic elastic tissue. Connect Tissue Res 1998;37:121-41.

7 Wheatley HM, Traboulsi EI, Flowers BE, et al. Immunohistochemical localization of fibrillin in human ocular tissues. Relevance to the Marfan syndrome. Arch Ophthalmol 1995;113:103-9.

68 Haynes SL, Shuttleworth CA, Kielty CM. Keratinocytes express fibrillin and assemble microfibrils: implications for dermal matrix organization. Br f Dermatol 1997;137:17-23.

69 Ross JM, McIntire LV, Moake JL, et al. Fibrillin containing elastic microfibrils support platelet adhesion under dynamic shear conditions. Thromb Haemost 1998;79:155-61.

70 Gibson MA, Sandberg LB, Grosso LE, Cleary EG. Complementary DNA cloning establishes microfibril- 
associated glycoprotein (MAGP) to be a discrete component of the elastin-associated microfibrils. 7 Biol Chem nent of the elastin-
1991;266:7596-601.

71 Gibson MA, Kumaratilake JS, Cleary EG. The protein components of the 12-nanometer microfibrils of elastic and nonelastic tissues. F Biol Chem 1989;264:4590-8.

72 Gibson MA, Hughes JL, Fanning JC, Cleary EG. The major antigen of elastin-associated microfibrils is a $31-\mathrm{kDa}$ glycoprotein. $\mathcal{F}$ Biol Chem 1986;261:11429-36.

73 Brown-Augsburger P, Broekelmann T, Mecham L, et al. Microfibril-associated glycoprotein binds to the carboxylterminal domain of tropoelastin and is a substrate for transglutaminase. F Biol Chem 1994;269:28443-9.

transglutaminase. F Biol Chem 1994;269:28443-9.
74 Finnis ML, Gibson MA. Microfibril-associated glycoprotein-1 (MAGP-1) binds to the pepsin-resistant domain of the $\alpha 3$ (VI) chain of type VI collagen. f Biol Chem domain of the $\alpha 3$ (VI)

75 Brown-Augsburger P, Broekelmann T, Rosenbloom J, Mecham RP. Functional domains on elastin and microfibril-associated glycoprotein involved in elastic fibre assembly. Biochem $\mathcal{F}$ 1996;318:149-55.

76 Henderson M, Polewski R, Fanning JC, Gibson MA. Microfibril-associated glycoprotein-1 (MAGP-1) is specifically located on the beads of the beaded-filament structure for fibrillin-containing microfibrils as visualized by the rotary shadowing technique. F Histochem Cytochem 1996; 44:1389-97.

77 Gibson MA, Hatzinikolas G, Kumaratilake JS, et al. Further characterization of proteins associated with elastic fiber microfibrils including the molecular cloning of MAGP-2 (MP25). F Biol Chem 1996;271:1096-103.

78 Hatzinikolas G, Gibson MA. The exon structure of the human MAGP-2 gene. Similarity with the MAGP-1 gene is confined to two exons encoding a cysteine-rich region. $f$ Biol Chem 1998;273:29309-14

79 Gibson MA, Leavesley DI, Ashman LK. Microfibrilassociated glycoprotein-2 specifically interacts with a range of bovine and human cell types via $\alpha_{\mathrm{V}} \beta_{3}$ integrin. $\mathcal{F}$ Biol Chem 1999;274:13060-5.

80 Gibson MA, Finnis ML, Kumaratilake JS, Cleary EG. Microfibril-associated glycoprotein-2 (MAGP-2) is specifiMicrofibril-associated glycoprotein-2 (MAGP-2) is specifi-
cally associated with fibrillin-containing microfibrils but cally associated with fibrillin-containing microfibrils but
exhibits more restricted patterns of tissue localization and exhibits more restricted patterns of tissue localization and developmental expression than its structural

81 Horrigan SK, Rich CB, Streeten BW, Li ZY, Foster JA Characterization of an associated microfibril protein through recombinant DNA techniques. F Biol Chem 1992; 267:10087-95.

82 Yeh H, Chow M, Abrams WR, et al. Structure of the human gene encoding the associated microfibrillar protein Genomics 1994;23:443-9.

83 Liu W, Faraco J, Qian C, Francke U. The gene for microfibril-associated protein-1 (MFAP1) is located several megabases centromeric to FBN1 and is not mutated in eral megabases centromeric to FBN1 and is not

84 Abrams WR, Ma RI, Kucich U, et al. Molecular cloning of the microfibrillar protein MFAP3 and assignment of the gene to human chromosome 5q32-q33.2. Genomics 1995 26:47-54.

85 Smith-Mungo LI, Kagan HM. Lysyl oxidase: properties, regulation and multiple functions in biology. Matrix Bio 1998;16:387-98.

86 Kobayashi R, Tashima Y, Masuda H, et al. Isoolation and characterization of a new $36-\mathrm{kDa}$ microfibril-associated glycoprotein from porcine aorta. $\mathcal{F}$ Biol Chem 1989;264: glycoprotein

87 Zhao Z, Lee CC, Jiralerspong S, et al. The gene for a human microfibril-associated glycoprotein is commonly deleted in Smith-Magenis syndrome patients. Hum Mol Genet 1995;4: 589-97.

88 Xia S, Ozsvath K, Hirose H, Tilson MD. Partial amino acid sequence of a novel $40-\mathrm{kDa}$ human aortic protein, with vitronectin-like, fibrinogen-like, and calcium binding domains: aortic aneurysm-associated protein-40 (AAAP40) (human MAGP-3, proposed). Biochem Biophys Res Commun 1996;219:36-9.

89 Hirose H, Ozsvath KJ, Xia S, Tilson MD. Molecular cloning of the complementary DNA for an additional member of the family of aortic aneurysm antigenic proteins. $\mathcal{F}$ Vasc Surg 1997;26:313-18.

90 Sasaki T, Mann K, Wiedemann H, et al. Dimer model for the microfibrillar protein fibulin-2 and identification of the
connecting disulfide bridge. $E M B O f 1997 ; 16: 3035-43$.

91 Reinhardt DP, Sasaki T, Dzamba BJ, et al. Fibrillin-1 and fibulin-2 interact and are colocalized in some tissues. $\mathcal{F} \mathrm{Biol}$ Chem 1996:271:19489-96.

92 Raghunath M, Tschodrich-Rotter M, Sasaki T, Meuli M, Chu ML, Timpl R. Confocal laser scanning analysis of the association of fibulin-2 with fibrillin-1 and fibronectin define different stages of skin regeneration. F Invest Dermatol 1999;112:97-101.

93 Sasaki T, Gohring W, Pan TC, Chu ML, Timpl R. Binding of mouse and human fibulin-2 to extracellular matrix ligands. F Mol Biol 1995;254:892-9.

94 Pan TC, Kluge M, Zhang RZ, Mayer U, Timpl R, Chu ML. Sequence of extracellular mouse protein BM-90/fibulin and its calcium-dependent binding to other basementmembrane ligands. Eur F Biochem 1993;215:733-40.

95 Adam S, Gohring W, Wiedemann H, Chu ML, Timpl R, Kostka G. Binding of fibulin-1 to nidogen depends on its
C-terminal globular domain and a specific array of calcium-binding epidermal growth factor- like (EG) modules. 7 Mol Biol 1997;272:226-36.

96 Tran H, Tanaka A, Litvinovich SV, Medved LV, Haudenschild CC, Argraves WS. The interaction of fibulin-1 with fibrinogen. A potential role in hemostasis and thrombosis. f Biol Chem 1995;270:19458-64.

97 Balbona K, Tran H, Godyna S, Ingham KC, Strickland DK, Argraves WS. Fibulin binds to itself and to the carboxylterminal heparin-binding region of fibronectin. 7 Biol Chem 1992;267:20120-5.

98 Tran H, VanDusen WJ, Argraves WS. The self-association and fibronectin-binding sites of fibulin-1 map to calciumbinding epidermal growth factor-like domains. $7 \mathrm{Biol} \mathrm{Chem}$ 1997;272:22600-6.

99 Roark EF, Keene DR, Haudenschild CC, Godyna S, Little $\mathrm{CD}$, Argraves WS. The association of human fibulin-1 with CD, Argraves WS. The association of human fibulin-1 with elastic fibers: an immunohistological, ultrastructur

100 Rupp P, Maslen C. Interaction of the fibrillins with laminin $\beta 2$ identified by yeast two hybrid analysis (abstract). Eur $\mathcal{F}$ Pediatr 1996;155:736.

101 Timpl R, Brown JC. The laminins. Matrix Biol 1994;14: 275-81.

102 Bressan GM, Daga-Gordini D, Colombatti A, Castellani I, Marigo V, Volpin D. Emilin, a component of elastic fibers preferentially located at the elastin-microfibrils interface. $\mathcal{F}$ Cell Biol 1993;121:201-12.

103 Hurle JM, Kitten GT, Sakai LY, Volpin D, Solursh M. Elastic extracellular matrix of the embryonic chick heart: an immunohistological study using laser confocal microscopy. Dev Dyn 1994;200:321-32

04 Kielty CM, Whittaker SP, Shuttleworth CA. Fibrillin: evidence that chondroitin sulphate proteoglycans are components of microfibrils and associate with newly synthesised monomers. FEBS Lett 1996;386:169-73.

105 Raghunath M, Superti-Furga A, Godfrey M, Steinmann B. Decreased extracellular deposition of fibrillin and decorin in neonatal Marfan syndrome fibroblasts. Hum Genet 1993;90:511-15.

106 Superti-Furga A, Raghunath M, Willems PJ. Deficiencies of fibrillin and decorin in fibroblast cultures of a patient with neonatal Marfan syndrome. F Med Genet 1992;29: 875-8.

107 Zimmermann DR, Dours-Zimmermann MT, Schubert $M$, Bruckner-Tuderman L. Versican is expressed in the proliferating zone in the epidermis and in association with the elastic network of the dermis. F Cell Biol 1994;124:81725

108 Maddox BK, Sakai LY, Keene DR, Glanville RW. Connective tissue microfibrils. Isolation and characterization of hree large pepsin-resistant domains of fibrillin. 7 Biol Chem 1989;264:21381-5.

109 Trask TM, Ritty TM, Broekelmann T, Tisdale C, Mecham RP. N-terminal domains of fibrillin 1 and fibrillin 2 direct the formation of homodimers: a possible first step in microfibril assembly. Biochem ₹ 1999;340:693-701.

110 Kielty CM, Raghunath M, Siracusa LD, et al. The Tight skin mouse: demonstration of mutant fibrillin-1 production and assembly into abnormal microfibrils. F Cell Biol 1998; 140:1159-66.

111 Bowness JM, Tarr AH. $\varepsilon(\gamma$-glutamyl)lysine crosslinks are concentrated in a non-collagenous microfibrillar fraction of cartilage. Biochem Cell Biol 1997;75:89-91.

112 Raghunath M, Bächi T, Aeschlimann D, Steinmann B. Fibrillin, the main component of elastic microfibrils, is modified by transglutaminase in cultured dermal fibroblasts and human dermis (abstract). Eur $\mathcal{f}$ Pediatr 1996;155:735.

113 Qian RQ, Glanville RW. Alignment of fibrillin molecules in elastic microfibrils is defined by transglutaminase-derived

114 Kielty CM, Shuttleworth CA. Abnormal fibrillin assembly by dermal fibroblasts from two patients with Marfan syndrome. F Cell Biol 1994;124:997-1004.

15 Raghunath M, Kielty CM, Kainulainen K, Child A, Peltonen L, Steinmann B. Analyses of truncated fibrillin caused by a 366 bp deletion in the FBN1 gene resulting in Marfan syndrome. Biochem f 1994;302:889-96.

116 Liu W, Qian C, Comeau K, Brenn T, Furthmayr H, Francke U. Mutant fibrillin-1 monomers lacking EGF-like domains disrupt microfibril assembly and cause severe Marfan syndrome. Hum Mol Genet 1996;5:1581-7.

117 Collod-Beroud G, Beroud C, Ades L, et al. Marfan database (third edition): new mutations and new routines for the software. Nucleic Acids Res 1998;26:229-3.

118 Dietz HC, Pyeritz RE. Mutations in the human gene for fibrillin-1 (FBN1) in the Marfan syndrome and related disorders. Hum Mol Genet 1995;4:1799-809.

119 Hayward C, Brock DJ. Fibrillin-1 mutations in Marfan syndrome and other type-1 fibrillinopathies. Hum Mutat 1997; 10:415-23.

120 Tynan K, Comeau K, Pearson M, et al. Mutation screening of complete fibrillin-1 coding sequence: report of five new mutations, including two in 8-cysteine domains. Hum $\mathrm{Mol}$ Genet 1993;2:1813-21.

121 Kainulainen K, Karttunen L, Puhakka L, Sakai L, Peltonen L. Mutations in the fibrillin gene responsible for dominant ectopia lentis and neonatal Marfan syndrome. Nat Genet 1994;6:64-9.

122 Nijbroek G, Sood S, McIntosh I, et al. Fifteen novel FBN1 mutations causing Marfan syndrome detected by heteroduplex analysis of genomic amplicons. Am $\mathcal{f}$ Hum Genet 1995;57:8-21. 
123 Hayward C, Porteous ME, Brock DJ. Mutation screening of all 65 exons of the fibrillin-1 gene in 60 patients with Marfan syndrome: report of 12 novel mutations. Hum :280-9.

124 Dietz HC, Kendzior RJ Jr. Maintenance of an open reading frame as an additional level of scrutiny during splice site selection. Nat Genet 1994;8:183-8.

125 Dietz HC, Valle D, Francomano CA, Kendzior RJ Jr, Pyeritz RE, Cutting GR. The skipping of constitutive exons in vivo induced by nonsense mutations. Science 1993;259. 680-3.

126 Liu W, Qian C, Francke U. Silent mutation induces exon skipping of fibrillin-1 gene in Marfan syndrome. Nat Genet 1997;16:328-9.

127 Booms P, Cisler J, Mathews KR, et al. Novel exon skipping mutation in the fibrillin-1 gene: two 'hot spots' for the neonatal Marfan syndrome. Clin Genet 1999;55:110-17.

128 Godfrey $M$, Raghunath $M$, Cisler J, et al. Abnormal morphology of fibrillin microfibrils in fibroblast cultures from patients with neonatal Marfan syndrome. Am $\mathcal{F}$ Pathol 1995;146:1414-21.

129 Edwards MJ, Challinor CJ, Colley PW, et al. Clinical and linkage study of a large family with simple ectopia lentis linked to FBN1. Am $\mathcal{F}$ Med Genet 1994;53:65-7

130 Tsipouras P, Del Mastro R, Sarfarazi M, et al. Genetic linkage of the Marfan syndrome, ectopia lentis, and congenital contractural arachnodactyly to the fibrillin genes on chromosomes 15 and 5. The International Marfan Syndrome Collaborative Study. $N$ Engl $7 \mathrm{Med}$ 1992;326:905-9.

131 Lönnqvist L, Child A, Kainulainen K, Davidson R, Puhakka L, Peltonen L. A novel mutation of the fibrillin gene causing ectopia lentis. Genomics 1994;19:573-6.

132 Greally MT, Carey JC, Milewicz DM, et al. ShprintzenGoldberg syndrome: a clinical analysis. Am $\mathcal{f}$ Med Genet 1998;76:202-12.

133 Sood S, Eldadah ZA, Krause WL, McIntosh I, Dietz HC. Mutation in fibrillin-1 and the Marfanoid-craniosynostosis (Shprintzen-Goldberg) syndrome. Nat Genet 1996;12:20911.

134 Watanabe Y, Yano S, Koga Y, et al. P1148A in fibrillin-1 is not a mutation leading to Shprintzen-Goldberg syndrome. Hum Mutat 1997;10:326-7.

135 Schrijver I, Liu W, Francke U. The pathogenicity of the Pro1 148Ala substitution in the FBN1 gene: causing or predisposing to Marfan syndrome and aortic aneurysm, or clinically innocent? Hum Genet 1997;99:607-11.

136 Wirtz MK, Samples JR, Kramer PL, et al. Weill-Marchesani syndrome-possible linkage of the autosomal dominant form to 15 q21.1. Am ₹ Med Genet 1996;65:68-75.

137 Hayward C, Porteous ME, Brock DJ. A novel mutation in the fibrillin gene (FBN1) in familial arachnodactyly. Mol the fibrillin gene (FBN1)
Cell Probes 1994;8:325-7.

138 Montgomery RA, Geraghty MT, Bull E, et al. Multiple molecular mechanisms underlying subdiagnostic variant of Marfan syndrome. Am f Hum Genet 1998;63:1703-11.

139 Francke U, Berg MA, Tynan K, et al. A Gly1127Ser mutation in an EGF-like domain of the fibrillin-1 gene is a risk factor for ascending aortic aneurysm and dissection. $A m \mathcal{F}$ Hum Genet 1995;56:1287-96.

140 Whiteman P, Downing AK, Smallridge R, Winship PR, Handford PA. A Gly $\rightarrow$ Ser change causes defective folding in vitro of calcium-binding epidermal growth factor-like domains from factor IX and fibrillin-1. F Biol Chem 1998 273:7807-13.

141 Milewicz DM, Michael K, Fisher N, Coselli JS, Markello T, Biddinger A. Fibrillin-1 (FBN1) mutations in patients with thoracic aortic aneurysms. Circulation 1996;94:2708with

142 Milewicz DM, Chen H, Park ES, et al. Reduced penetrance and variable expressivity of familial thoracic penetrance and variable expressivity of fal 1998;82:474-9.

143 Viljoen D. Congenital contractural arachnodactyly (Beals syndrome). F Med Genet 1994;31:640-3.

44 Putnam EA, Zhang H, Ramirez F, Milewicz DM. Fibrillin-2 (FBN2) mutations result in the Marfan-like disorder, congenital contractural arachnodactyly. Nat Genet 1995;11:456-8

145 Putnam EA, Park ES, Aalfs CM, Hennekam RC, Milewicz DM. Parental somatic and germ-line mosaicism for a FBN2 mutation and analysis of FBN2 transcript levels in dermal fibroblasts. Am ₹ Hum Genet 1997;60:818-27.

146 Wang M, Clericuzio CL, Godfrey M. Familial occurrence of typical and severe lethal congenital contractural arachnodactyly caused by missplicing of exon 34 of fibrillin-2. Am odactyly caused by missplicing

147 Maslen C, Babcock D, Raghunath M, Steinmann B. A rare branch-point mutation is associated with missplicing of fibrillin-2 in a large family with congenital contractura arachnodactyly. Am f Hum Genet 1997;60:1389-98.

148 Park ES, Putnam EA, Chitayat D, Child A, Milewicz DM Clustering of FBN2 mutations in patients with congenital contractural arachnodactyly indicates an important role of the domains encoded by exons 24 through 34 during human development. Am F Med Genet 1998;78:350-5.

149 Babcock D, Gasner C, Francke U, Maslen C. A single mutation that results in an Asp to His substitution and partial exon skipping in a family with congenital contractural arachnodactyly. Hum Genet 1998;103:22-8.

150 Maquat LE. When cells stop making sense: effects of nonsense codons on RNA metabolism in vertebrate cells. RNA 1995;1:453-65.

151 Dietz HC, McIntosh I, Sakai LY, et al. Four novel FBN1 mutations: significance for mutant transcript level and
EGF-like domain calcium binding in the pathogenesis of Marfan syndrome. Genomics 1993;17:468-75.

152 Herskowitz I. Functional inactivation of genes by dominant negative mutations. Nature 1987;329:219-22.

153 Stenflo J, Lundwall A, Dahlback B. $\beta$-Hydroxyasparagine in domains homologous to the epidermal growth factor precursor in vitamin K-dependent protein S. Proc Natl Acad Sci USA 1987;84:368-72.

154 Mayhew M, Handford P, Baron M, Tse AG, Campbell ID, Brownlee GG. Ligand requirements for $\mathrm{Ca}^{2+}$ binding to EGF-like domains. Protein Eng 1992;5:489-94.

155 Selander-Sunnerhagen M, Ullner M, Persson E, Teleman $\mathrm{O}$, Stenflo J, Drakenberg T. How an epidermal growth factor (EGF)-like domain binds calcium. High resolution NMR structure of the calcium form of the NH2-terminal EGF- like domain in coagulation factor X. F Biol Chem 1992;267:19642-9.

156 Corson GM, Chalberg SC, Dietz HC, Charbonneau NL, Sakai LY. Fibrillin binds calcium and is coded by cDNAs that reveal a multidomain structure and alternatively spliced exons at the 5' end. Genomics 1993;17:476-84.

157 Smallridge RS, Whiteman P, Doering K, Handford PA, Downing AK. EGF-like domain calcium affinity modulated by N-terminal domain linkage in human fibrillin-1. $\mathcal{f}$ Mol Biol 1999;286:661-8.

158 Rao Z, Handford P, Mayhew M, Knott V, Brownlee GG, Stuart D. The structure of a $\mathrm{Ca}(2+)$-binding epidermal growth factor-like domain: its role in protein-protein interactions. Cell 1995;82:131-41.

159 Rand MD, Lindblom A, Carlson J, Villoutreix BO, Stenflo J. Calcium binding to tandem repeats of EGF-like modules. Expression and characterization of the EGF-like modules of human Notch-1 implicated in receptor-ligand interactions. Protein Sci 1997;6:2059-71.

160 Downing AK, Knott V, Werner JM, Cardy CM, Campbell ID, Handford PA. Solution structure of a pair of calcium-binding epidermal growth factor-like domains: implications for the Marfan syndrome and other genetic disorders. Cell 1996;85:597-605.

161 Knott V, Downing AK, Cardy CM, Handford P. Calcium binding properties of an epidermal growth factor-like domain pair from human fibrillin-1. F Mol Biol 1996;255: 22-7.

162 Cardy CM, Handford PA. Metal ion dependency of microfibrils supports a rod-like conformation for fibrillin-1 calcium-binding epidermal growth factor-like domains. $f$ Mol Biol 1998;276:855-60.

163 Kielty CM, Shuttleworth CA. The role of calcium in the organization of fibrillin microfibrils. FEBS Lett 1993;336: 323-6.

164 Reinhardt DP, Mechling DE, Boswell BA, Keene DR, Sakai LY, Bachinger HP. Calcium determines the shape of fibrillin. $\mathcal{F}$ Biol Chem 1997;272:7368-73.

165 Engel J. EGF-like domains in extracellular matrix proteins: ocalized signals for growth and differentiation? FEBS Lett 1989;251:1-7.

166 Kettle S, Yuan X, Grundy G, Knott V, Downing AK, Handford PA. Defective calcium binding to fibrillin-1: consequence of an $\mathrm{N} 2144 \mathrm{~S}$ change for fibrillin-1 structure and function. $7 \mathrm{Mol}$ Biol 1999;285:1277-87.

167 Rebay I, Fleming RJ, Fehon RG, et al Specific EGF repeats of Notch mediate interactions with Delta and Serrate: implications for Notch as a multifunctional receptor. Cell 1991;67:687-99.

68 Sasaki T, Mann K, Murphy G, Chu ML, Timpl R. Different susceptibilities of fibulin-1 and fibulin- 2 to cleavage by matrix metalloproteinases and other tissue proteases. Eur 7 Biochem 1996;240:427-34.

169 Colosetti P, Hellman U, Heldin $\mathrm{CH}$, Miyazono K. $\mathrm{Ca}^{2+}$ binding of latent transforming growth factor- $\beta 1$ binding protein. FEBS Lett 1993;320:140-4.

170 Öhlin AK, Stenflo J. Calcium-dependent interaction between the epidermal growth factor precursor-like region of human protein $\mathrm{C}$ and a monoclonal antibody. $\mathcal{F} \mathrm{Biol}$ Chem 1987;262:13798-804.

171 Kielty CM, Woolley DE, Whittaker SP, Shuttleworth CA. Catabolism of intact fibrillin microfibrils by neutrophil elastase, chymotrypsin and trypsin. FEBS Lett 1994;351: $85-9$

172 Ashworth JL, Murphy G, Rock MJ, et al. Fibrillin degradation by matrix metalloproteinases: implications for connective tissue remodelling. Biochem f 1999;340:171-81.

173 Winship PR, Dragon AC. Identification of haemophilia B patients with mutations in the two calcium binding domains of factor IX: importance of a $\beta-\mathrm{OH}$ Asp $64 \rightarrow$ Asn change. Br f Haematol 1991;77:102-9.

174 Handford P, Downing AK, Rao Z, Hewett DR, Sykes BC, Kielty CM. The calcium binding properties and molecular organization of epidermal growth factor-like domains in human fibrillin-1. 7 Biol Chem 1995;270:6751-6.

175 Karttunen L, Raghunath M, Lonnqvist L, Peltonen L. A compound-heterozygous Marfan patient: two defective fibrillin alleles result in a lethal phenotype. Am f Hum Genet 1994;55:1083-91.

176 Fleischer KJ, Nousari HC, Anhalt GJ, Stone CD, Laschinger JC. Immunohistochemical abnormalities of fibrillin in cardiovascular tissues in Marfan's syndrome. Ann Thorac Surg 1997;63:1012-17.

177 Godfrey M, Menashe V, Weleber RG, et al. Cosegregation of elastin-associated microfibrillar abnormalities with the Marfan phenotype in families. Am f Hum Genet 1990;46: 652-60. 
178 Kielty CM, Shuttleworth CA. Synthesis and assembly of fibrillin by fibroblasts and smooth muscle cells. 7 Cell $S c i$ fibrillin by fibroblast

179 Milewicz DM, Pyeritz RE, Crawford ES, Byers PH. Marfan syndrome: defective synthesis, secretion, and extracellular matrix formation of fibrillin by cultured dermal fibroblasts. F Clin Invest 1992;89:79-86.

180 Aoyama T, Tynan K, Dietz HC, Francke U, Furthmayr H. Missense mutations impair intracellular processing of fibrillin and microfibril assembly in Marfan syndrome. Hum Mol Genet 1993;2:2135-40.

181 Aoyama T, Francke U, Dietz HC, Furthmayr H. Quantitative differences in biosynthesis and extracellular deposition of fibrillin in cultured fibroblasts distinguish five groups of Marfan syndrome patients and suggest distinct pathogenetic mechanisms. $\mathcal{F}$ Clin Invest 1994;94:130-7.

182 Aoyama T, Francke U, Gasner C, Furthmayr H. Fibrillin abnormalities and prognosis in Marfan syndrome and related disorders. Am 7 Med Genet 1995;58:169-76.

183 Booms P, Withers AP, Boxer M, et al. A novel de novo mutation in exon 14 of the fibrillin-1 gene associated with mutation in exon 14 of the fibrillin-1 gene associated with delayed secretion of fibrillin in a patient with
phenotype. Hum Genet 1997; 100:195-200.

184 Kielty CM, Phillips JE, Child AH, Pope FM, Shuttleworth CA. Fibrillin secretion and microfibril assembly by Marfan dermal fibroblasts. Matrix Biol 1994;14:191-9.

185 Kielty CM, Davies SJ, Phillips JE, Jones CJ, Shuttleworth CA, Charles SJ. Marfan syndrome: fibrillin expression and microfibrillar abnormalities in a family with predominan ocular defects. F Med Genet 1995;32:1-6.

186 Besser TE, Potter KA, Bryan GM, Knowlen GG. An animal model of the Marfan syndrome. Am 7 Med Genet 1990;37:159-65.

187 Potter KA, Besser TE. Cardiovascular lesions in bovine Marfan syndrome. Vet Pathol 1994;31:501-9.

188 Potter KA, Hoffman Y, Sakai LY, Byers PH, Besser TE, Milewicz DM. Abnormal fibrillin metabolism in bovine Marfan syndrome. Am f Pathol 1993;142:803-10.
189 Pereira L, Andrikopoulos K, Tian J, et al. Targetting of the gene encoding fibrillin-1 recapitulates the vascular aspect of Marfan syndrome. Nat Genet 1997;17:218-22.

190 Siracusa LD, McGrath R, Ma Q, et al. A tandem duplication within the fibrillin 1 gene is associated with the mouse tight skin mutation. Genome Res 1996;6:300-13.

191 Kilpatrick MW, Phylactou LA, Godfrey M, Wu CH, Wu GY, Tsipouras P. Delivery of a hammerhead ribozyme specifically down-regulates the production of fibrillin-1 by cultured dermal fibroblasts. Hum Mol Genet 1996;5:1939-44.

192 Montgomery RA, Dietz HC. Inhibition of fibrillin 1 expression using U1 snRNA as a vehicle for the presentation of antisense targeting sequence. Hum Mol Genet 1997;6:519-25.

193 Phylactou LA, Tsipouras P, Kilpatrick MW. Hammerhead ribozymes targeted to the FBN1 mRNA can discriminate a single base mismatch between ribozyme and target. Biochem Biophys Res Commun 1998;249:804-10.

194 Kanzaki T, Olofsson A, Moren A, et al. TGF- $\beta 1$ binding protein: a component of the large latent complex of TGF- $\beta 1$ with multiple repeat sequences. Cell 1990;61: 1051-61.

195 Faraco J, Bashir M, Rosenbloom J, Francke U. Characterization of the human gene for microfibril-associated glycoprotein (MFAP2), assignment to chromosome 1p36.1-p35, and linkage to D1S170. Genomics 1995;25: 630-7.

196 Ståhl-Hallengren C, Ukkonen T, Kainulainen K, et al. An extra cysteine in one of the non-calcium-binding epidermal growth factor-like motifs of the FBN1 polypeptide is connected to a novel variant of Marfan syndrome. $\mathcal{F}$ Clin Invest 1994;94:709-13.

197 Black C, Withers AP, Gray JR, et al. Correlation of a recurrent FBN1 mutation (R122C) with an atypical familial Marfan syndrome phenotype. Hum Mutat 1998;suppl: S198-200. 